\title{
The Neolithic Settlement of Highland SW Iran: New Evidence from the Mamasani District
}

\section{Citation}

Weeks, Lloyd, Karim Alizadeh, Lily Niakan, Kourosh Alamdari, Mohsen Zeidi, Alireza

Khosrowzadeh, and Bernadette McCall. 2006. "The Neolithic Settlement of Highland SW Iran:

New Evidence from the Mamasani District." Iran 44: 1-31.

\section{Published Version}

http://www.jstor.org/stable/4300702

\section{Permanent link}

http://nrs.harvard.edu/urn-3:HUL.InstRepos:12553721

\section{Terms of Use}

This article was downloaded from Harvard University's DASH repository, and is made available under the terms and conditions applicable to Other Posted Material, as set forth at http:// nrs.harvard.edu/urn-3:HUL.InstRepos:dash.current.terms-of-use\#LAA

\section{Share Your Story}

The Harvard community has made this article openly available.

Please share how this access benefits you. Submit a story.

Accessibility 


\section{Volume XLIV 2006}

\section{CONTENTS}

Page

Governing Council .... . . . . . . . . . . . . . . . . . . il ii

Report of the Council ....................... iii

Obituaries . . . . . . . . . . . . . . . . . . . . . . . . v v

The Neolithic Settlement of Highland SW Iran: new evidence from the Mamasani District, by Lloyd Weeks,

Karim Alizadeh, Lily Niakan, et al. . . . . . . . . . . . . . . . . . . . . .

Socio-economic transformations: settlement survey in the Tehran Plain and excavations at Tepe Pardis, by R.A.E Coningham, H. Fazeli, R.L. Young, et al. . . . . . . . . . . . . . . . . .

The Bushehr Hinterland: results of the first season of the Iranian-British Archaeological Survey of Bushehr Province, November-December 2004, by R.A. Carter, K. Challis, S.M.N. Priestman and H. Tofighian.

Egyptian hieroglyphs on Achaemenid period cylinder seals, by Mariana Giovino . . . . . . . . 105

The Oxus Scabbard, by John Boardman ．． . . . . . . . . . . . . . . . . . 115

Linear barriers of northern Iran: the great wall of Gorgan and the wall of Tammishe, by Jebrael Nokandeh, Eberhard Sauer, Hamid Omrani Rekavandi, et al.

The "Tradition of Mufaddal". and the doctrine of the Raj'a: evidence of Ghuluww in the eschatology of Twelver Shicism?, by Colin P. Turner . . . . . . . . . . . . . . . . . . . . .

New Data on the Appanage Rulers of Khuttalān and Wakhsh, by Michael Fedorov . . . . . . . . 197

The Friday Mosque at Simnān, by Alireza Anisi . . . . . . . . . . . . . . . . . . . . . 207

Monuments of Bamiyan Province, Afghanistan, by Jonathan Lee . . . . . . . . . . . . . . 229

Environmental evidence from the Minaret of Jam Archaeological Project, Afghanistan, by D.C. Thomas, K. Deckers, M.M. Hald, et al. . . . . . . . . . . . . . . . . . . . . . . . . . 253

The rise and fall of the Banū Ka‘b. A borderer state in southern Khuzestan, by Willem Floor • • • . 277

Years amongst the Persians: Maria Browne's letters from Iran, by Alice Browne ～. . . . . . . . . 317

The Shāhnāmeh in Bakhtiāri Nomadic Society: anthropological aspects of hero and heroism, by Pedram

Khosronejad . . . . . . . . . . . . . . . . . . . 321

Altars, precincts, and temples: medieval and modern Zoroastrian praxis, by Jamsheed K. Choksy 327

Archaeological Reports . . . . . . . . . . . . . . . . . . . . . . . . . 347

THE BRITISH INSTITUTE OF PERSIAN STUDIES Registered Charity No. 231161

c/o The British Academy, 10 Carlton House Terrace, London SW1Y 5AH ISSN 0578-6967 


\title{
THE NEOLITHIC SETTLEMENT OF HIGHLAND SW IRAN: NEW EVIDENCE FROM THE MAMASANI DISTRICT
}

\author{
By Lloyd Weeks, Karim Alizadeh, Lily Niakan, Kourosh Alamdari, \\ Mohsen Zeidi, Alireza Khosrowzadeh and Bernadette McCall \\ Nottingham, Tehran and Sydney
}

Since November 2002, the Mamasani Archaeological Project, a collaborative research initiative between the Iranian Centre for Archaeological Research (ICAR) and the University of Sydney, has been conducting fieldwork in highland SW Iran (see Fig. 1). This article takes the opportunity to present a discussion of one facet of our fieldwork, specifically, the evidence for the earliest Neolithic communities in highland Fars. ${ }^{1}$

\section{"NEOLITHIC" FARS}

As a review of the recent literature on early food producing groups in the Old World indicates, the Neolithic is not what it used to be. Indeed, although the basic equation of Neolithic societies with food production still lies at the heart of most conceptions of the Neolithic, even this notion has come under scrutiny in debates that stress the conceptual, ideological, and social aspects of Neolithic transitions (e.g. Thomas 1991; Pluccienik 1998; Hodder 1998; Bernbeck 2001). Other dichotomies that distinguished Neolithic and nonNeolithic societies in traditional models of the Agricultural Revolution (e.g. settled vs. mobile, complex vs. egalitarian, high population density vs. low population density) have also in many instances failed to stand up to close scrutiny, and are more often now regarded as end points on spectrums of behaviour which characterise both Neolithic and non-Neolithic groups. In general, recent discussions have stressed the variability of Neolithic adaptations seen in the archaeological record, the problems associated with reifying the normative and essentialising concepts of "farmer" and "forager", and the difficulties of assuming a strict developmental sequence from one to the other (see e.g. papers in Bailey et al. 2005, Edmonds and Richards 1998, and Harris 1996).

The recognition of the variability in Neolithic adaptations has direct implications for the usefulness of the label "Neolithic" and demands that, at the least, our discussions are explicit about what constitutes the characteristic elements of Neolithic societies in our region of study. This requirement immediately introduces problems for the discussion of "Neolithic" communities in highland SW Iran, as we have virtually no information on some of the most basic aspects of their economy and subsistence: little idea of whether or what kind of agriculture and animal husbandry they practised; how important this was in comparison to hunting and foraging; whether settlements were occupied seasonally or on a more sedentary basis; and what proportion of the community was mobile and to what extent. In essence, Neolithic sites in Fars are labelled as such for historical reasons as much as for any clear archaeological evidence of farming or sedentism. Their material assemblages incorporate elements such as pottery and mudbrick/chineh architecture that were part of the traditional conception of the "Neolithic package" (cf. Pluccienik 1998: 62) at the time these sites were first identified. Following this reasoning, if some components of this package were present, then the others (in this case agriculture and animal husbandry) were also assumed to have been present. Hence, "Neolithic" Fars.

There are, of course, good reasons to think that these communities do deserve to be labelled Neolithic. For example, the predominant site location on valley floors suitable for agriculture suggests an agricultural subsistence base for Neolithic communities in Fars, and the likely development of spring irrigation systems by the latest phase of Neolithic settlement in the Kur River Basin (Sumner 1994: 59) further supports this idea. The "Neolithic package" argument is also relatively convincing on a regional scale, as there are numerous contemporary and earlier sites nearby in Iran with similar material culture, where clear archaeological evidence for agriculture and animal husbandry has been documented (e.g. Zeder and Hesse 2000; Hole 1996; 


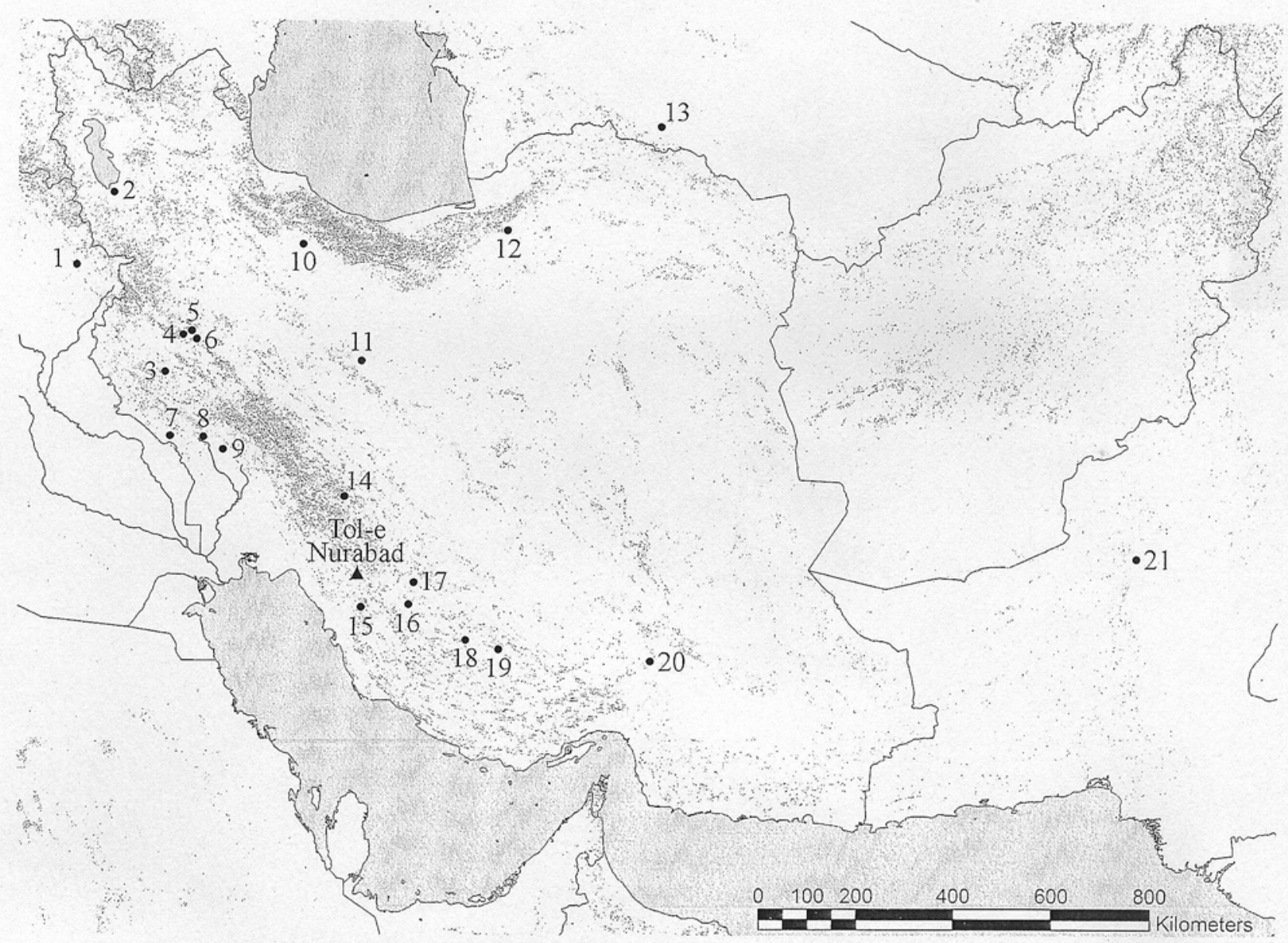

Fig. 1. Map of Neolithic sites in Iran and adjacent regions mentioned in the text, showing the location of Tol-e Nurabad in the Mamasani District, Fars Province. Sites: 1. Jarmo. 2. Hajji Firuz Tepe. 3. Tepe Guran. 4. Tepe Sarab. 5. Ganj Dareh. 6. Tepe Abdul Hossein. 7. Ali Kosh. 8. Tepe Tula'i. 9. Susiana (Chogha Bonut, Chogha Mish). 10. Qazvin Plain (Cheshme Ali, Tepe Zagheh). 11. Tepe Sialk. 12. Sang-e Chaqmak. 13. Jeitun. 14. Qale Rostam. 15. Tall-i Morge. 16. Shiraz (Kutahi). 17. Kur River Basin (Tall-i Mushki, Tall-i Jari A and B, Tall-i Bakun B, Toll-e Bashi, Kushk-e Hezar). 18. Fasa. 19. Darab. 20. Soghun and Daulatabad valleys (Tepe Yahya VII, Tepe Gaz Tavila). 21. Mehrgarh.

Hole 1987a; Van Zeist et al. 1984). However, as recent debates have emphasised, to label sites as Neolithic is inadequate in and of itself, and often obscures more than it reveals. Our ultimate task is to determine the specific economic and social adaptations that characterise and define "Neolithic" sites.

In highland SW Iran, however, the achievement of such a goal is a long way off. Our existing database on Neolithic settlements in the region is very limited, meaning that work must proceed first with the development of basic chronological, environmental, subsistence and material culture frameworks. Thus, in the present article we emphasise the importance of the material recovered from our research in Mamasani for the construction of an absolute and relative chronology for Neolithic Fars. Nevertheless, as it is the nature of archaeological evidence that a sherd can be both chronological marker and cultural signifier, our article concludes with a series of speculative discussions which trace some implications of the new material from Mamasani. These discussions touch on basic theoretical concerns regarding the variability of Neolithic adaptations, and thus introduce issues more closely tied to the reality and individuality of Neolithic transitions in Fars: issues of local Neolithic origins, settlement growth, and phases of regional isolation and integration. 


\section{PREVIOUS RESEARCH ON NEOLITHIC FARS}

Although what would today be regarded as evidence for Neolithic settlement in Fars was recorded in excavation and surveys as early as the 1920s. (Stein 1936: pl. XXIII.93, 95-100; Schmidt 1937, 1939), ${ }^{2}$ the first systematic investigation of Neolithic sites in the Kur River Basin was that conducted by Louis Vanden Berghe in the early 1950s (Vanden Berghe 1952, 1954). The evidence from Vanden Berghe's surveys has been supplemented by subsequent large scale regional surveys in the Kur River Basin undertaken by William Sumner (1972, 1990), John Alden (1979), Michael Rosenberg (2003) and Paul Gotch (1968) in the late 1960 s and 1970s, and by survey in the Fasa and Darab regions conducted by Pierre De Miroschedji in the early 1970s (Miroschedji 1972). Excavations at Neolithic sites in Fars have been much rarer, incorporating Stein's rapid excavations at sites across Fars (Stein 1936; Dittmann 1986: 343-66), Vanden Berghe's small test trenches at Tall-i Mushki and Tall-i Jari (Vanden Berghe 1954), and more substantial excavations by researchers from Tokyo University at Tall-i Mushki (Fukai et al. 1973), Tall-i Jari A and B (Egami et al. 1977; Egami 1967), and Tall-i Bakun B (Egami and Masuda 1962), in addition to the material from the lower levels of the Oriental Institute soundings at Tall-i Bakun B in the 1930s (Schmidt 1937, 1939). Despite intensive survey prior to 1979 , no clear evidence was recovered for proto-Neolithic or aceramic Neolithic occupation in the region (Sumner 1977, 1990; Rosenberg 2003), ${ }^{3}$ indicating the possibility of a long chronological gap in the settlement of the Kur River Basin from the end of Epipalaeolithic (Zarzian) period in the terminal Pleistocene to the first ceramic Neolithic period settlements of the early to mid-Holocene.

These early excavations and surveys indicated that initial Neolithic occupation in the region was represented by groups using painted, chaff-tempered, soft ware pottery of the type found during the Japanese and Belgian excavations at Tall-i Mushki and Tall-i Jari (A and B). The relative chronology of these ceramic assemblages was far from clear: whilst Vanden Berghe (1954) suggested that Jari pottery pre-dated Mushki pottery, the larger excavations by the Japanese team suggested that pottery of the Mushki style was the earliest (Fukai et al. 1973). Significantly, neither Vanden Berghe nor the Japanese team observed a clear stratigraphic relationship between typical Mushki and Jari wares during excavation at any one site. The third and final component of the Neolithic sequence for the Kur River Basin recognised in this early period of research was characterised by undecorated, chaff tempered, soft ware ceramics which were initially known as Bakun B1 ware but later christened "Shamsabad" ware by Sumner (1980). Shamsabad pottery was found stratified above Jari pottery at Tall-i Jari A, and below black-on-buff painted Bakun pottery at Tall-i Jari A and Tall-i Bakun B (Egami et al. 1977; Egami and Masuda 1962; Vanden Berghe 1954; Schmidt 1937, 1939). The excavation data outlined above were used to order the ceramic Neolithic settlements in the Kur River Basin into a simple tripartite chronological division based on the type-site concept, comprising (earliest to latest) the Mushki, Jari and Shamsabad periods.

This relative chronology, in particular the chronological priority of Mushki wares over Jari wares, was supported by the data from survey in the Kur River Basin, where Sumner (1994: tab. 1) recorded 8 Mushki period sites, 50 Jari period sites, and 108 Shamsabad period sites, suggesting a clear progression and expansion of Neolithic settlement in the area from its earliest to latest phases. Likewise, stylistic analyses of excavated ceramics from Tall-i Jari B (Maeda 1986) supported the idea that Mushki ware was in fact the earliest of the three main ceramic assemblages recorded in the Kur River Basin, although a conclusive stratigraphic demonstration of this relationship remains to be provided.

Even in this initial stage of research, however, it was apparent that the established periodisation of the Neolithic material remains from the Kur River Basin could not be easily or satisfactorily generalised to wider Fars. Mushki pottery was relatively widespread, being recorded not only in the Kur River Basin area but also near Sarvestan, south-east of Shiraz (Stein 1936: pl. XXIII.93, 95-100; Dittmann 1986: fig. 10.2-5), and at the site of Tall-i Morge near Kazerun in western Fars (Sumner 1977). In contrast, Jari pottery was recorded at few sites outside the Kur River Basin, and it seemed likely that in the period when the Kur River Basin sites were predominantly characterised by Jari pottery, distinctive wares produced using a similar ceramic technology but with different painted designs were utilised in the Shiraz area (Kutahi ware), in Fasa and Darab (Jalyan and Bizdan wares), and in western Fars near Kazerun (Dittmann 1986; Sumner 1977; Miroschedji 1972). However, the relative chronology of 
these wares was impossible to establish based purely upon survey data, and their chronological relationship to the established Kur River Basin sequence was equally difficult to ascertain.

The absolute chronology developed for Neolithic sites in the Kur River Basin was based on an even less certain footing than the relative ceramic chronology outlined above. Although the Neolithic ceramics from Fars show a general similarity with ceramics of the Zagros Neolithic group and lowland SW Iran (e.g. Voigt and Dyson 1992: 136; Sumner 1977: 299), clear and specific typological and decorative parallels with ceramic assemblages in neighbouring regions are sparse. ${ }^{4}$ Furthermore, the crossdating approach generally suffered from the fact that the external assemblages were themselves rarely more securely dated than their counterparts in Fars. Such studies thus represented, more often, efforts in relative ceramic chronology building on a supra-regional scale rather than the establishment of absolute chronological frameworks, and tended to highlight the technological similarity of the so-called "Neolithic soft wares" found across much of Iran (cf. Vandiver 1987; Dyson 1965) rather than any specific shared decorative motifs.

Other evidence for the absolute dating of Neolithic sites in Fars was very rare. The radiocarbon evidence for the Mushki and Jari periods incorporated only a handful of samples, reflecting in part the limited excavation of contemporary sites. The small number of radiocarbon dates were characterised by large standard deviations, and were often highly divergent from each other and from expected age ranges (Hole 1987a: tab. 3; Voigt and Dyson 1992: tab. 2). In general, the ceramic typologies and radiocarbon dates suggested that the Mushki and Jari periods should be placed in the 6th millennium B.C., although the absolute dates given by different authorities within this timeframe could vary by as much as half a millennium (e.g. Hole 1987a: tab. 2; Voigt and Dyson 1992: fig. 2). Two radiocarbon determinations on charcoal taken (after excavation) from the standing sections at Tall-i Bakun B indicate an absolute date range for the Shamsabad period from the last few centuries of the 6th millennium B.C. into the earlier 5th millennium B.C. (Stuckenrath 1963: 90; Stuckenrath et al. 1966: 350). ${ }^{5}$ However, whether this range represents the entire Shamsabad chronological span or just a part of it cannot be determined due to the lack of clear contextual information for the analysed samples.

In summary, excavations at Neolithic settlements in Fars in the 1950s and 1960s generated a basic Mushki-
Jari-Shamsabad relative ceramic chronology for the Kur River Basin, which when teamed with the results of large-scale regional survey (Sumner 1972, 1990) was able to provide some information on the development of local Neolithic settlement systems. These early excavations were, in many respects, characterised by a culture historical approach rather than the more ecological approach that was being developed by Frank Hole and colleagues on near-contemporary excavations at Neolithic sites in Deh Luran (Hole et al. 1969). Thus, there was an emphasis on typological studies of ceramics and lithics from Neolithic Fars, but less interest in establishing the range of subsistence practices that supported the populations of these sites, or on the permanence (or otherwise) of occupation on the mounds. Although data on site location and irrigation systems derived from surveys in the Kur River Basin provided some information on possible agricultural practices (e.g. Sumner 1990, 1994), critical studies of the floral and faunal assemblages from the excavated sites were not undertaken, and thus no information was available regarding issues such as specific plant and animal husbandry practices or the utilisation of wild resources.

\section{NEW FIELDWORK ON NEOLITHIC FARS}

Our knowledge of Neolithic Fars has recently been supplemented by a number of new field projects and related publications. These include excavations and/or surveys in the Kur River Basin at Toll-e Bashi (Abdi et al. 2003; Bernbeck et al. 2003), Tall-i Mushki, Tall-i Jari A and B, and Tall-i Bakun B (Alizadeh 2004), and Kushk-e Hezar (Alden et al. 2004), in addition to salvage excavations in the Tang-e Bolaghi (Tsuneki and Zeidi in prep.), surveys in the valleys to the NW and SW of the Kur River Basin (Alizadeh 2003a; Bernbeck et al. 2005), and the ICAR/USyd excavations and survey in the Mamasani District (Potts and Roustaei in press). The research agendas of these new projects reflect developments in archaeological techniques, theories, and approaches since the 1970s and show a theoretically-informed focus upon broad issues related to the Neolithisation of Fars (see e.g. Bernbeck et al. 2003; Petrie et al. in press b). Nevertheless, the thirty year hiatus in field research on the Neolithic communities of Fars has meant that new projects beginning work in the region must closely reexamine even the most basic and seemingly established 


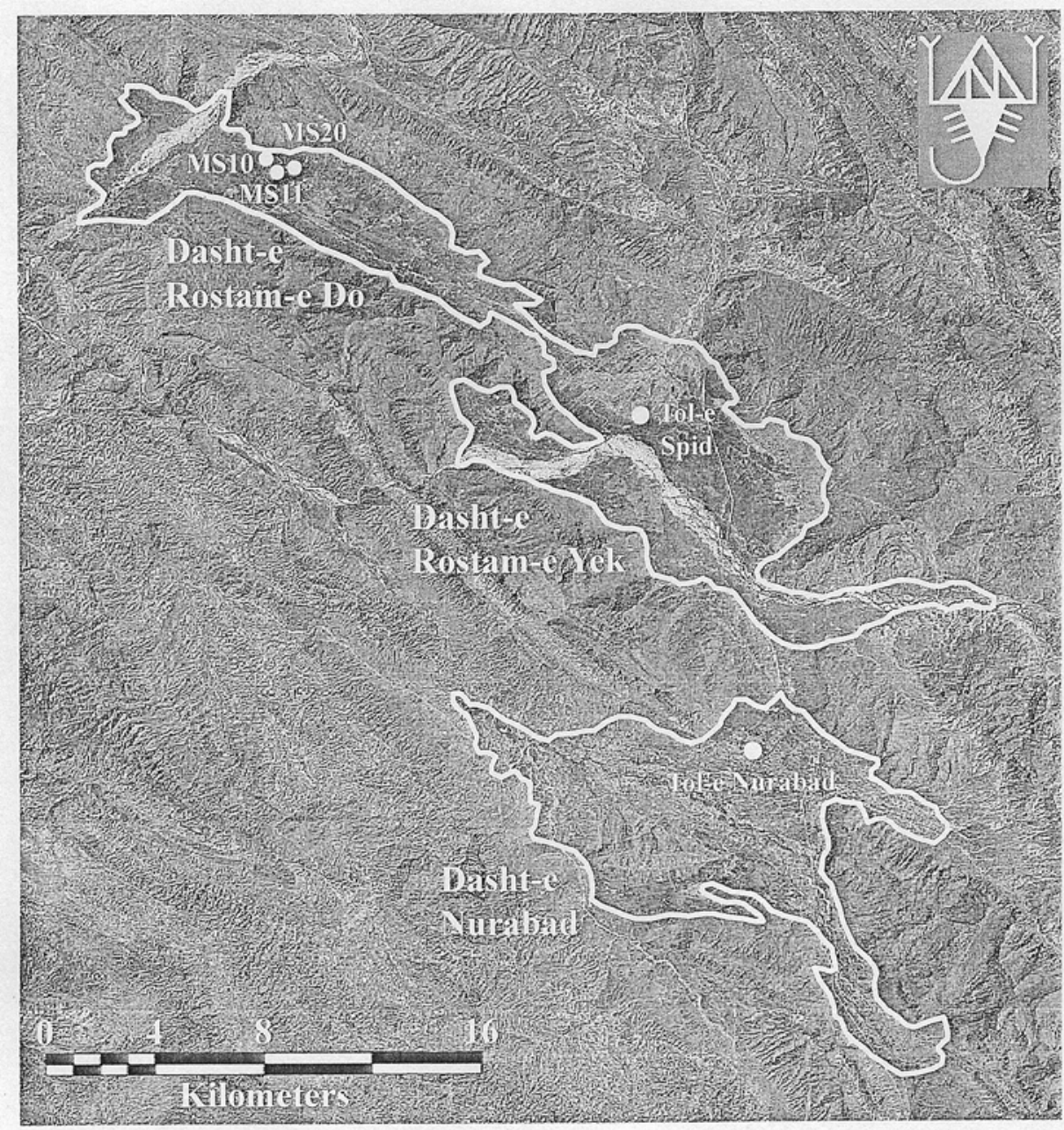

Fig. 2. A Landsat 7 satellite image of the ICAR/USyd Mamasani Archaeological Project study area, showing the location of the excavated sites of Tol-e Nurabad and Tol-e Spid.

aspects of these societies. In the following sections, the contributions made by the Mamasani Archaeological Project to our understanding of Neolithic Fars are outlined, with a focus upon the implications of our data for the absolute and relative chronology of this period.

\section{The Mamasani Archaeological Project}

Research conducted under the auspices of the Mamasani Archaeological Project has thus far incorporated archaeological survey and excavations in the valleys of Dasht-e Rostam-e Yek, Dasht-e Rostam-e Do and Dasht-e Nurabad, which together comprise a major part of the Mamasani District of western Fars Province (Fig. 2). Deep soundings were excavated at the large mounded sites of Tol-e Spid in the Dasht-e Rostam-e Yek and Tol-e
Nurabad in the Dasht-e Nurabad in February-March and June-July 2003. The excavations at Tol-e Spid (Petrie et al. in press a) revealed a very long sequence of discontinuous occupation from the Lapui period (early 4th millennium B.C.) to the post-Achaemenid period, with the possibility of earlier, as-yet-unsampled Chalcolithic and Neolithic deposits. Excavations at Tole Nurabad (Weeks et al. in press) revealed an even longer sequence stretching from the pottery Neolithic period to the post-Achaemenid period. The stratified archaeological material excavated from these mounds provided a sound and relatively precise basis from which to establish the periods of occupation at sites recorded during a brief reconnaissance survey of the Dasht-e Rostam-e Yek and Do conducted over two weeks in February-March 2003 (Zeidi et al. in press). This preliminary survey focused upon the recording of 


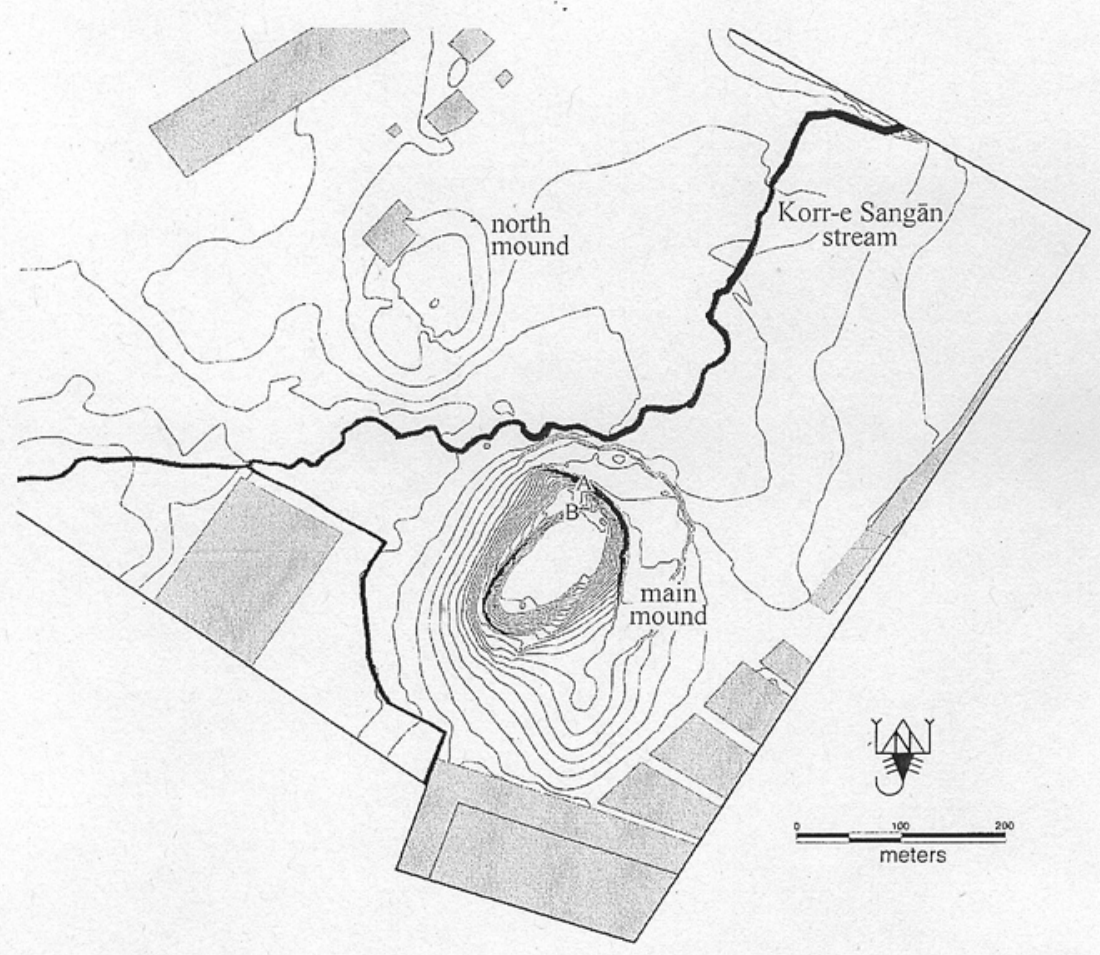

Fig. 3. Topographic plan of Tol-e Nurabad and environs, showing locations of trenches $A$ and $B$ (labelled) and modern buildings (grey shaded). mounded sites on the valley floors, and revealed evidence for human settlement in the region from the Neolithic period to the recent past.

Most significantly for the present article, excavations at Tol-e Nurabad revealed a long sequence of stratified Neolithic deposits, and it is this material, in addition to that from the survey, that provides the impetus for the present discussion. Tol-e Nurabad (Fig. 3) is the largest surviving mounded site in the Mamasani District. It is situated at c. $965 \mathrm{~m}$. altitude, survives to a height of c. 23 $\mathrm{m}$. above the surrounding plain, and covers an area of $c$. 9 ha: A smaller, lower mound exists a few hundred metres to the north-north-west of the main mound, separated from it by a small permanent stream, the spring-fed Korr-e Sangan. The main mound has been substantially disturbed by earth-moving activities, exposing a number of steep sections on its northern edge. Our small trenches at the site exploited this disturbance: Trench A was placed on the edge of the tallest cut through the mound which had exposed a sloping section roughly $10 \mathrm{~m}$. high, whilst Trench B was located on a smaller sloping section at the highest point of the mound. Both trenches were excavated in a step-wise fashion down the faces of the exposed sections and eventually below ground level, with the aim that, when combined, they would sample a depositional column through the entire surviving height of the mound. The section from the excavation of Trench A is shown in Figure 4. The total depth of Trench A is approximately $15 \mathrm{~m}$., and excavated exposures varied from c. $4-5 \mathrm{~m} .{ }^{2}$ in the higher levels of the trench to $2 \mathrm{~m}^{2}$ at its base. The upper $10 \mathrm{~m}$. of Trench A consisted of archaeological deposits that could be dated using ceramic finds and radiocarbon determinations from the Bakun period in the 5th millennium B.C. to the late Kaftari or Qaleh periods in the mid-2nd millennium B.C. Trench B deposits continued this sequence, and were dated by ceramic finds from the Middle Elamite period in the later 2nd millennium B.C. to the post-Achaemenid period (see Weeks et al. in press).

The lowest $5 \mathrm{~m}$. of deposits in Trench A contained deposits dated exclusively to the ceramic Neolithic period. This material represents the earliest known occupation layers at the site, and comprises Phases A19 (highest/youngest) to A27 (lowest/oldest), which sits upon virgin soil. As illustrated in Figure 5, these deposits consisted predominantly of superimposed architecture from houses and elaborate house installations such as hearths. The remains for the earliest phase, A27, are very limited, consisting only of a concentration of ash in the SE corner of the small sounding. Following from this phase, substantial mudbrick and chineh architecture 

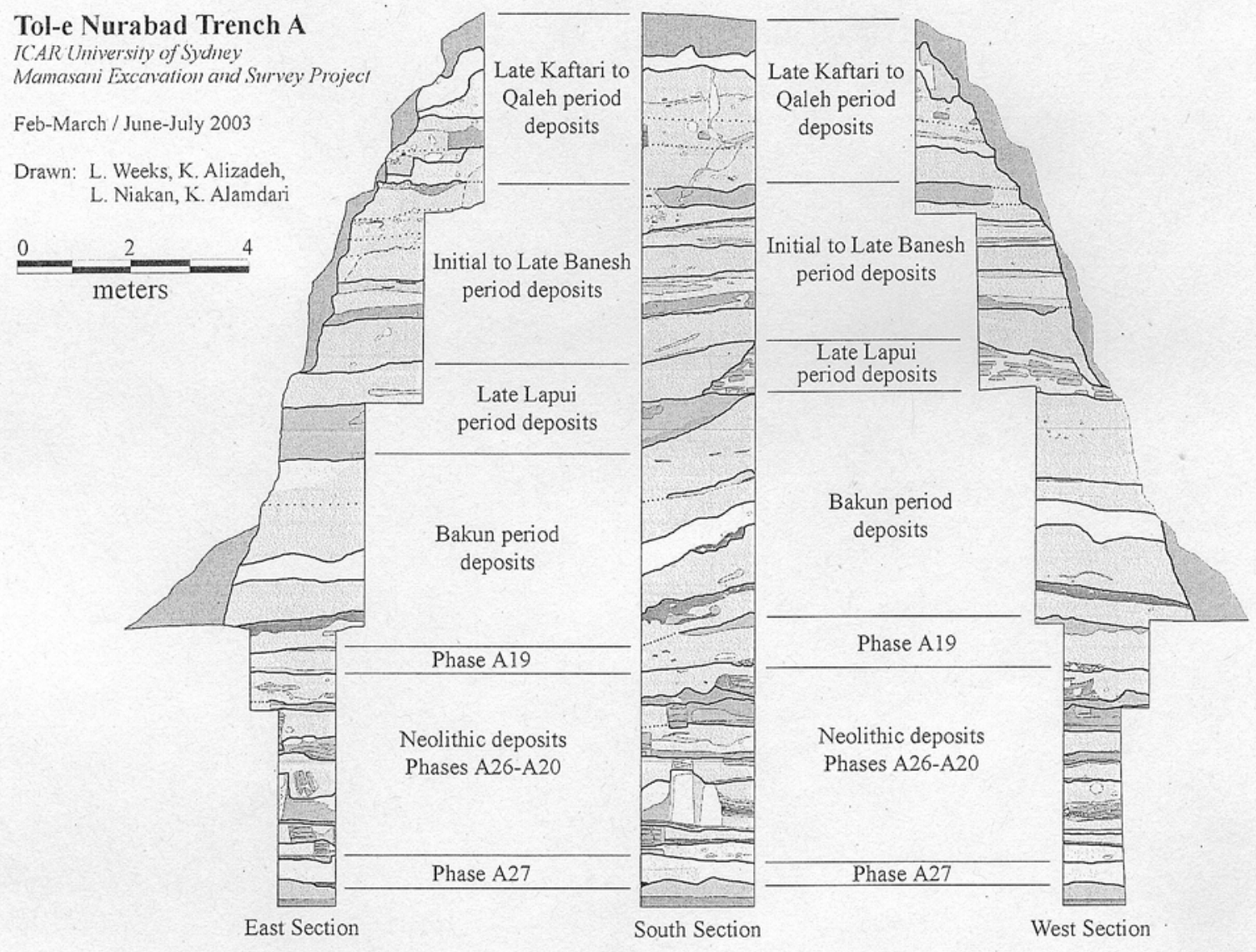

Fig. 4. The Tol-e Nurabad trench A sections. Neolithic occupational deposits are represented by Phases A19 to A27 at the base of the trench.

and/or hearths are recorded in Phases A26 to A20, before another phase of less substantial remains in the latest Neolithic deposits of Phase A19. As seen in Figure 5, the consistency of orientation of the structures recorded in these phases is remarkable, and the walls of Phases A24b to A21 generally share not only orientation but precise location. It is perhaps unsurprising, then, that although the deposits of Phases A26 to A20 represent the accumulation of c. $4 \mathrm{~m}$. of archaeological debris, the radiocarbon dates for charcoal from these phases cover a relatively short span in the early-mid 6th millennium B.C. (see Fig. 5). Calculations of the duration of phases $\mathrm{A} 26$ to $\mathrm{A} 20$ based on analysis of the radiocarbon dates using $\mathrm{OxCal}$ version 3.10 (Bronk Ramsey 1995, 2001) suggest a span of $80-350$ years at $95 \%$ confidence, i.e. only one or two generations of use for each of the eight structural phases. In contrast, the deposits of the latest Neolithic phase have produced two radiocarbon dates consistent in their placement of the Phase A19 in the early 5th millennium
B.C., suggesting a gap in occupation of approximately $790-1040$ years $(2 \sigma$ range calculated using OxCal 3.10) between Phases A20 and A19.

A substantial amount of material was excavated at Tol-e Nurabad in association with these Neolithic deposits, comprising primarily ceramics, animal bones and charred botanical remains. In addition, a small chipped stone assemblage of less than 100 pieces (Weeks et al. in press: 63) and a handful of small finds such as "labrets" and beads were recovered (Weeks et al. in press: fig. 3.189). The ceramic assemblages consisted primarily of chaff-tempered soft wares with a thick burnished slip, upon which elaborate geometric decoration was applied in red, brown and/or black paint. The painted ceramics from Phases A27 to A24b are illustrated in Figure 6, whilst the painted ceramics from Phases A24a to A19 are illustrated in Figure 7. Undecorated chaff-tempered soft ware ceramics, commonly slipped and burnished, were also recovered 


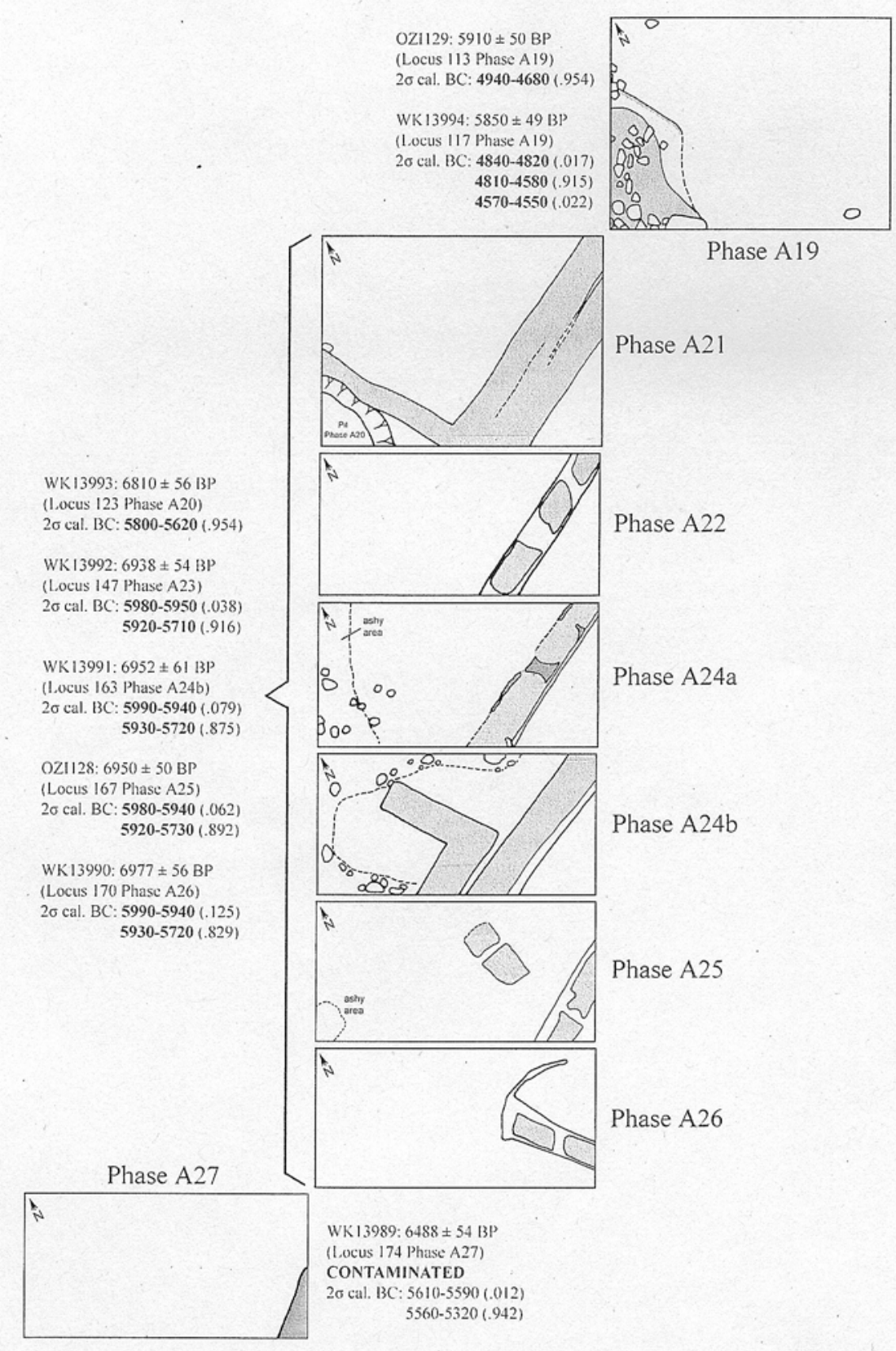

Fig. 5. Structural remains (mudbrick and chineh) and radiocarbon dates from various Neolithic occupational phases at Tol-e Nurabad.

from all Neolithic phases, as illustrated in Figure 8. Table 1 provides a summary of frequency data for a selection of the decorative motifs recorded at Tol-e Nurabad Phases A27 to A19, based upon registered sherds. The discussion in this paper summarises the ceramic evidence from Tol-e Nurabad and highlights the main chronological implications of the material. ${ }^{6}$ For a detailed presentation and discussion of the ceramics from the site, the reader is referred to relevant sections of the forthcoming monograph on the Mamasani Archaeological Project (Weeks et al. in press: 40-62 and figs. 3.65-3.188). 
TABLE 1. Frequencies of painted sherds from Tol e Nurabad bearing particular motif classes, organised by phase.

\begin{tabular}{|c|c|c|c|c|c|c|c|c|c|c|c|c|c|c|c|}
\hline & & &
\end{tabular}

\section{IMPLICATIONS OF THE MAMASANI EVIDENCE FOR THE CHRONOLOGY OF NEOLITHIC FARS}

As outlined above, the ceramic chronology of Neolithic Fars has been developed and debated over the course of the last 50 years, based upon relatively little archaeological evidence. Significant issues remaining unanswered include: 1) the chronological priority of Mushki ware over Jari ware, which has never been clearly demonstrated stratigraphically at any one archaeological site; 2) the degree to which the ceramic chronology of Neolithic Kur River Basin can be adequately characterised using the basic tripartite Mushki-Jari-Shamsabad formulation; 3) the viability of any established Kur River Basin relative chronology for the understanding of relative chronology in other regions of Fars; and 4) the absolute chronology of these ceramic assemblages. These issues are discussed below and the impact of material obtained during recent fieldwork in the Mamasani District and the Kur River Basin on our understanding is highlighted.

\section{Mushki and Jari pottery}

As illustrated in Figure 6 and Table 1, the material found in the earliest phase of Neolithic occupation at Tol-e Nurabad appears to represent pottery exclusively of the Mushki type known from the Kur River Basin. ${ }^{7}$ The ceramic assemblage from this phase consisted of only a handful of sherds, but nevertheless typical Mushki motifs (such as the line with terminal dot) can be seen on the sherds illustrated in Figure 6. Mushki pottery is also to be found in small quantities in a mixed Phase A27-A26 context (TNP 1811, 1813) and in Phases A26 (TNP 1789) and A25 (TNP 1763, 1764), where it is perhaps residual. Unfortunately, sherd sizes were too small to provide much useful information on vessel form, although two strongly carinated body sherds, a shape typical of the Mushki pottery from the Kur River Basin, were found in a mixed Phase A27-A26 context.

It is not until the following phase (A26) that any pottery similar to early Jari ware ${ }^{8}$ is recorded, and this consists of only one potentially intrusive sherd (TNP 1783). Larger Jari ware sherds which are much less 


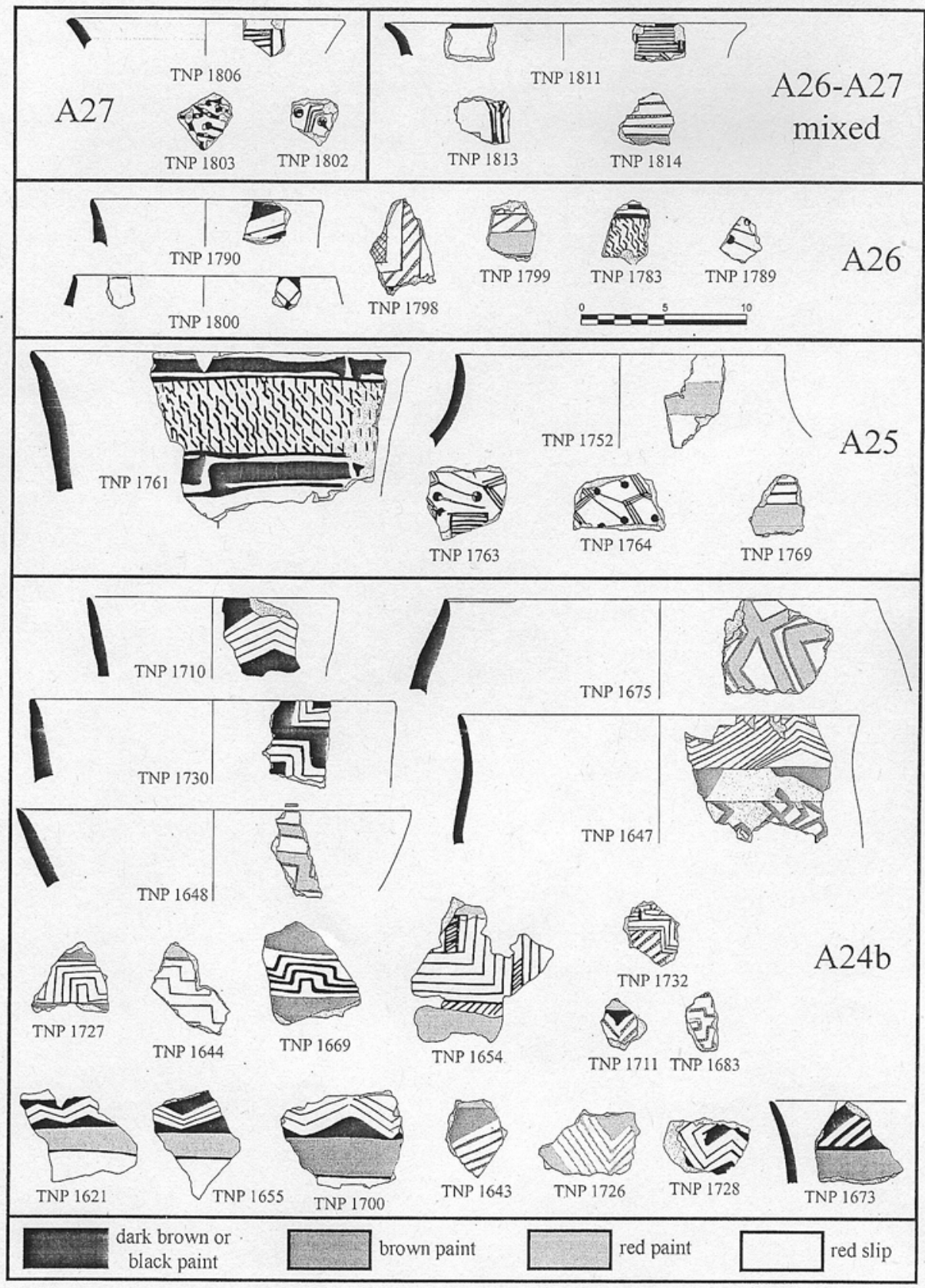

Fig. 6. Painted ceramics from Tol-e Nurabad Phases A27 to A24b. Graphical conventions for the representation of paint and slip colours are given at the bottom of the image. 


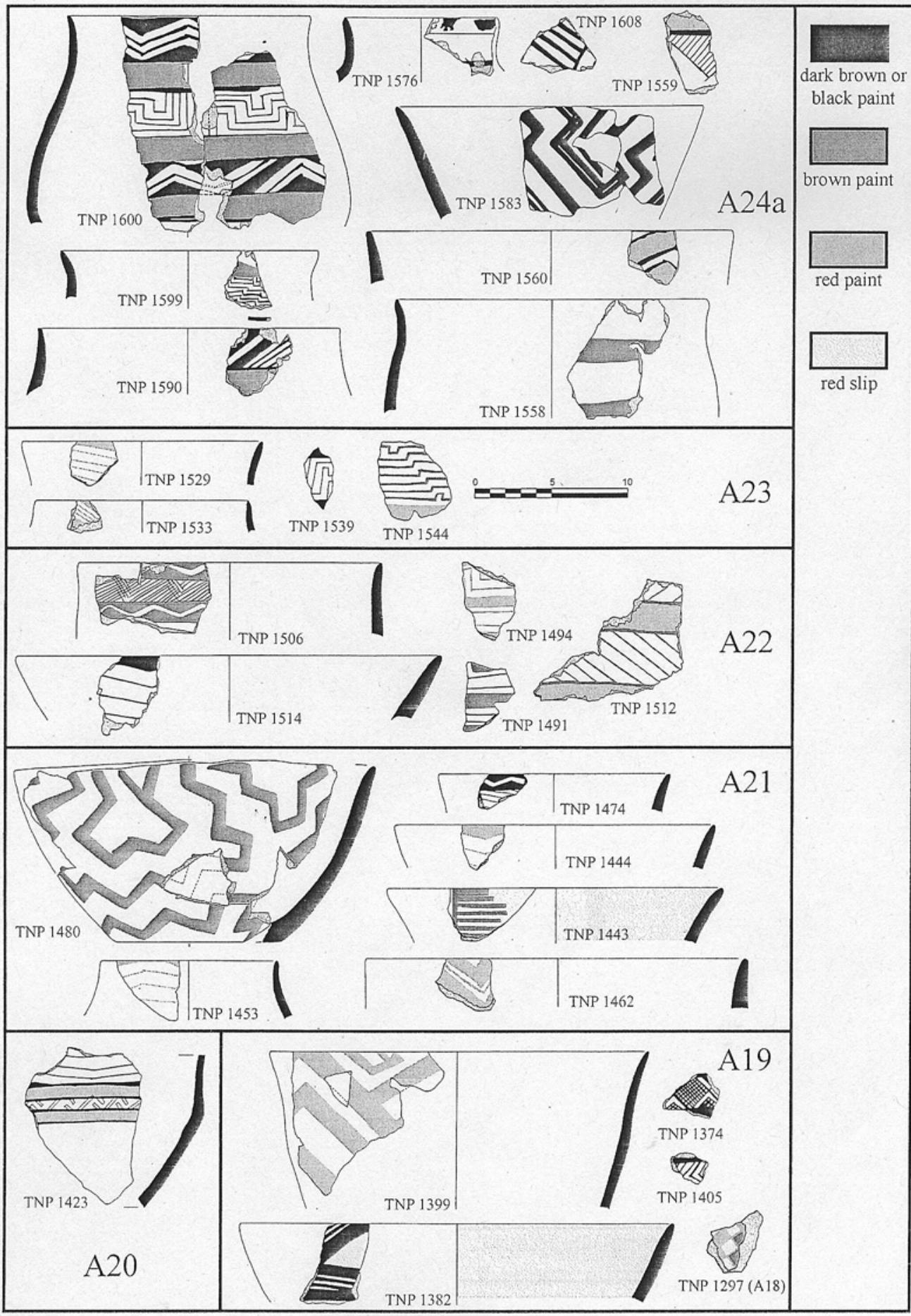

Fig. 7. Painted ceramics from Tol-e Nurabad Phases A24a to A19 (plus TNP 1297 from Phase A18). Graphical conventions for the representation of paint and slip colours are given at the right of the image. 


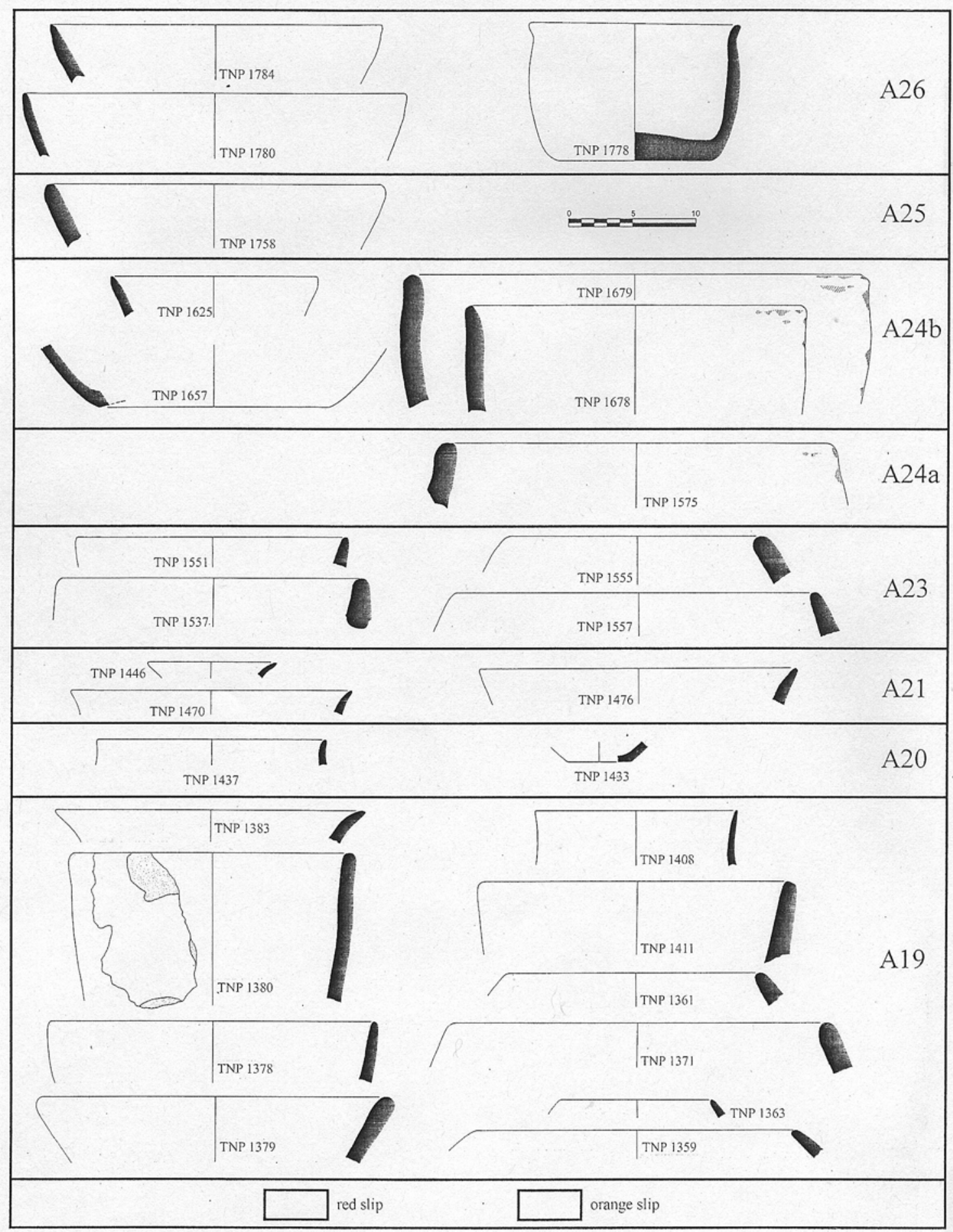

Fig. 8. Unpainted ceramics from Tol-e Nurabad Phases A26 to A19. Graphical conventions for the representation of slip colours are given at the bottom of the image. 
likely to be intrusive are found in Phase A25 (TNP 1761), where they comprise just under one-third of the registered ceramic assemblage ( 8 of a total 27 sherds). Four of these sherds are recognisable by the distinctive "chain" or "hook" motif well known from the Kur River Basin at Tall-i Jari B (Maeda 1986) and in the upper levels of Toll-e Bashi (R. Bernbeck pers. comm.). It is uncertain whether the Jari sherds from Tol-e Nurabad were imported from another area outside Mamasani, such as the Kur River Basin, or manufactured locally. The small number of Jari sherds at Tol-e Nurabad and their use of only one of the multiple decorative motifs known from Jari sites in the Kur River Basin support the idea that these vessels originated outside of Mamasani. ${ }^{9}$ Regardless, our excavations provide the first clear stratigraphic evidence that Mushki pottery, and by implication the Mushki period, does indeed pre-date Jari pottery and the Jari period.

\section{The viability of the tripartite periodisation for the Neolithic Kur River Basin}

The viability of the tripartite Mushki-Jari-Shamsabad division of the Neolithic ceramic sequence in the Kur River Basin has been closely scrutinised in the course of recent research in Fars. Already in the Japanese excavations at Tall-i Mushki and Tall-i Jari A it was apparent that painted pottery of a style different to "classic" Mushki or Jari pottery was to be found in the Kur River Basin. This was found at Tall-i Mushki in the TMB trench (Fukai et al. 1973: pls. XXIII-XXIV) and at Tall-i Jari A Level III, in association with more typical Jari pottery (Egami et al. 1977). This pottery is typified by the use of the "ladder" motif, consisting of pairs of closely spaced parallel lines with small dots/lines between them, groups of which are combined to form a variety of geometric patterns. In addition, pottery from the Mushki TMB trench and Tall-i Jari A Level III are characterised by the presence of a developed or derived Mushki-like design of diagonal lines with small terminal dots.

Recent excavations at Toll-e Bashi (Bernbeck et al. 2003; Abdi et al. 2003) have been critical in reassessing the chronological positioning of this ceramic style, and it is clear that such pottery, now known as "Bashi ware", should be positioned in relative chronological terms between the earlier Mushki wares and the later
Jari wares in the Kur River Basin (R. Bernbeck and S. Pollock, pers. comm.). The data from Tol-e Nurabad support such a chronological position for Bashi pottery. Here, the "ladder" motif is first recorded in a mixed Phase A27-A26 context and is most common in Phases A26-A24b (Fig. 6: TNP 1814, 1798, 1799; also Tab. 1), i.e. stratigraphically after the Mushki assemblage of Phase A27 and slightly earlier (in its first appearance) than the clear evidence for the use of early Jari pottery in Phase A25.

The new evidence and analyses highlight the fact that the traditional Mushki-Jari-Shamsabad division of the Neolithic ceramic assemblages from the Kur River Basin is too coarse to adequately represent the complexity of Neolithic cultural developments in Fars as a whole. It is clear that newly delineated ceramic assemblages from sites such as Toll-e Bashi and Kushk-e Hezar (Alden et al. 2004) must be inserted into this relative chronology at various points. Whether or not they are regarded as different assemblages or as just earlier and later phases of the traditional ware types is a matter of opinion..$^{10}$ As outlined in detail below (see Fig. 12), in this paper we advocate the introduction of only one "new" period (i.e. the Bashi period) and favour the further division of the Jari period into early and late phases.

As a final note on this issue, the co-occurrence of these various wares in different phases at Tol-e Nurabad and at sites in the Kur River Basin raises the question of whether the ware types indicate discrete, successive chronological periods or whether there was some overlap in the use of different ware types in Neolithic Fars. A model incorporating the notion of "battleship curves" as used in frequency seriation (i.e. the gradual replacement of one style by another) might partly account for the co-occurrence of Mushki, Bashi, and Jari wares at sites in the Kur River Basin and Mamasani. However, this issue is also complicated by the distinct possibility that material found out of chronological context at deep and reworked mounded sites such as Tol-e Nurabad and those in the Kur River Basin clouds the picture of the replacement of ceramic traditions in Neolithic Fars. For example, as can be seen in Table 1, Mushki sherds appear at various points throughout the Tol-e Nurabad Neolithic sequence in contexts in which they are almost certainly intrusive. Larger scale excavations will be required at Tol-e Nurabad and other sites in Mamasani in order to resolve these issues on a local scale. 


\section{Kur River Basin chronologies and other regions of Fars}

The clearest picture that emerges from a stylistic analysis of the Tol-e Nurabad ceramic assemblage, from as early as Phase A26 but particularly from Phase A24b onwards, is not one of similarity with other regions of Fars, but of the development of a distinctive painted ceramic tradition whose decorative elements show few parallels with better known ceramic traditions of the Kur River Basin (see Figs. 6 and 7 and Tab. 1). This local pottery tradition is characterised by the use of elaborate painted geometric decoration, and most noticeably by the use of bichrome painted decoration in red+black, red+darkbrown, or dark-brown+black. The predominant vessel forms are large bowls (e.g. TNP 1730, 1648, 1560, 1514, 1480 ) and slightly closed jar forms with a sinuous profile (e.g. TNP 1647, 1600, 1558, 1453). Closed forms with a very tight restriction at the neck or orifice are very rare (e.g. TNP 1576), as are strongly carinated forms.

Thus, it appears that we have yet another regional ceramic tradition to add to the lists compiled by Sumner (1977) and Dittmann (1986). Nevertheless, some of the distinctive elements of this local assemblage appear to have their roots in earlier traditions which occur in other regions of Fars. Two examples of this phenomenon are outlined here: the use of bichrome decoration, and the possible local/indigenous derivation of the stepped line motif from earlier Jari painted motifs.

In the first case, elaborate bichrome painted decoration is very prevalent at Tol-e Nurabad by Phase $\mathrm{A} 24 \mathrm{~b}$ and continues to be produced through to the end of the Neolithic sequence in decreasing frequency. However, the earliest bichrome painted wares at Tol-e Nurabad are found in a mixed Phase A26-A27 deposit, and it is clear that the origins of the later more elaborate bichrome painted pottery from Tol-e Nurabad are to be found in these earlier examples. Significantly, such decoration is not a feature found only on pottery from Mamasani: bichrome decoration in the form of alternating buff and red slip on vessels and red-brown painted bands also characterises elements of the classic Mushki and Mushki TMB pottery of the Kur River Basin (Fukai et al. 1973: pls. XVIII.1, XIX.3, XX.4, XXI.2.4, XXII.1.4, XXII.2.5, 8). Moreover, bichrome decoration of one form or another can be seen in a number of contemporary or earlier ceramic traditions in SW Iran, for example at Qale Rostam in the Bakhtiari mountains (Bernbeck 1989), at Kavar in the Qara Aghaj valley
(Bernbeck et al. 2005) and in low frequencies at Chogha Mish in the Archaic Susiana period (e.g. Delougaz and Kantor 1996: pl. 213.A,H, pl. 215.H,J, pl. 217.J,P).

The second case where indigenous Mamasani decorative motifs can perhaps be traced to earlier antecedents involves the development of a specific painted motif known from early Jari pottery in the Kur River Basin (also found at Tol-e Nurabad). As illustrated in Figure 9, pottery with the typical early Jari "chain" or "hook" motif known from the Kur River Basin is found in Phases A26-A25 (TNP 1783, 1761). Later deposits, however, appear to witness the development of this motif from a diagonally-oriented pattern to a much more horizontally/vertically-oriented form with more closely spaced lines. These possible "developed" or "derived" forms (see Fig. 9, right box) are found in a very limited chronological horizon at Tol-e Nurabad, in Phase A24b. Interestingly, this proposed pattern of stylistic development is distinct from that which can be traced at Jari period sites in the Kur River Basin, as outlined by the analyses of Maeda (1986), suggesting that it may be indigenous to Mamasani. It is possible, although far from certain, that the indigenous development of early Jari decorative motifs at Tol-e Nurabad from non-local antecedents led in turn to the appearance and elaboration of the stepped-line motif that characterises much of the pottery of Tol-e Nurabad Phases A24b-A23 (see Fig. 6: TNP 1727, 1669, 1644; Fig. 7: TNP1600, 1544, 1539).

Together, these examples highlight the heritage and inter-regional connections that underlay the development of the distinctive style of painted Neolithic pottery seen in Mamasani. The diversification and development of local decorative motifs and bichrome painting are most clearly seen from Phases A24b-A20, perhaps because the deposits of Phase A24a are amongst the deepest and richest from the Neolithic levels at the site, and the related ceramic assemblage is consequently larger. As illustrated in Figures 6 and 7 and Table 1, motifs prevalent from Phase A24b include the stepped-line and variations on the zigzag motif, and there are numerous motifs such as hatched triangles and monochrome oblique painted bands which occur less frequently and in slightly later contexts. Developments are also observable in the fineness of painted lines and in the use of monochrome decoration in red paint.

It is unfortunate that the long hiatus in the deposits at Tol-e Nurabad between Phases A20 and A19 makes it impossible at present to use excavated assemblages to trace the development of ceramic industries in Mamasani 


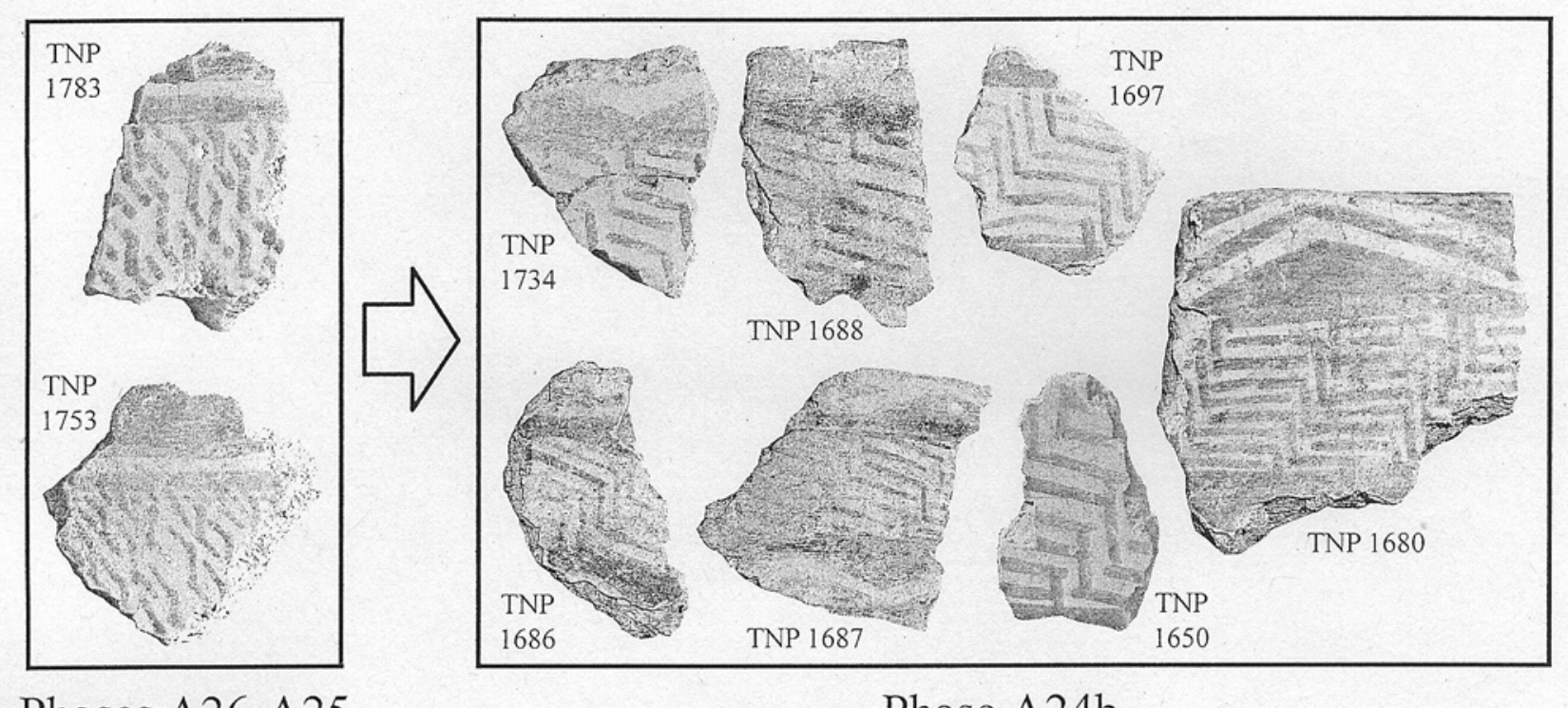

Phases A26-A25

Phase A24b

Fig. 9. A possible developmental sequence for Jari-related decorative motifs seen at Tol-e Nurabad, Phases A26-A24b.

from the mid-6th to the early 5th millennium B.C. However, Neolithic ceramics from Mamasani collected during surface reconnaissance survey may be significant for the discussion of this issue. As illustrated in Figure 10, a number of sherds collected from a cluster of Neolithic sites in the Dasht-e Rostam-e Do (known as MS-10, 11, and 20; see Zeidi et al. in press), exhibit a decorative style that is difficult to parallel with the excavated assemblages from Tol-e Nurabad. Whilst a number of these sherds can be clearly paralleled at Tol-e Nurabad (e.g. MSP 851, 855), it is possible that some of the remaining painted sherds from sites in the Dasht-e Rostam-e Do fit into the 800-1000 year gap in the Neolithic occupational sequence at Tol-e Nurabad. Likewise, a number of sherds found during surface collection at Tol-e Nurabad (Fig. 10, bottom row) cannot be readily paralleled with ceramics from the excavated sequence at the site, and are thus thought to date to the gap between Phases A20 and A19. These few sherds from surface collections at Tol-e Nurabad and elsewhere in Mamasani, in addition to those excavated from Phase A19 (see below), may represent the first known examples of the decorated ceramic styles of later Neolithic Mamasani.

Whilst the pottery of Phase A19 is technologically similar to that produced in Phases A27-A20, i.e. a hand made, chaff-tempered soft-ware with thick slip and burnish, there are some changes in ceramic assemblage composition that support the long chronological gap between Phases A19 and A20 indicated by the radiocarbon dates (see Fig. 5). Specifically, whilst the painted ceramic assemblage of Phase A19 is relatively small, a number of the registered sherds incorporate motifs that are stylistically distinct form earlier phases (Fig. 7: TNP 1374, 1382, and TNP 1297, a residual Neolithic sherd sound in Phase A18). Moreover, the proportion of plain wares is higher in Phase A19 than in the earlier layers, and as illustrated in Figure 8, they are more often red or reddish-orange than the buff or lightorange plain wares of preceding phases. The increased proportion of undecorated pottery in Tol-e Nurabad Phase A19 has parallels with the rise of the Shamsabad assemblage in later Neolithic Kur River Basin, and the typology of plain ware vessels recorded at Tol-e Nurabad is certainly comparable with the range of Shamsabad vessel forms.

Overall, the stylistic antecedents of the ceramics from Tol-e Nurabad can be paralleled most closely in the Mushki, Bashi and early Jari period assemblages of the Kur River Basin. As a result, a relative ceramic chronology of Neolithic Fars based upon typological/ stylistic comparisons is most easy to establish for the earlier periods, when there appears to be a wider distribution of specific ceramic styles across the province. The distinct regionalisation of ceramic styles in Neolithic Fars (contemporary with the Jari period) 


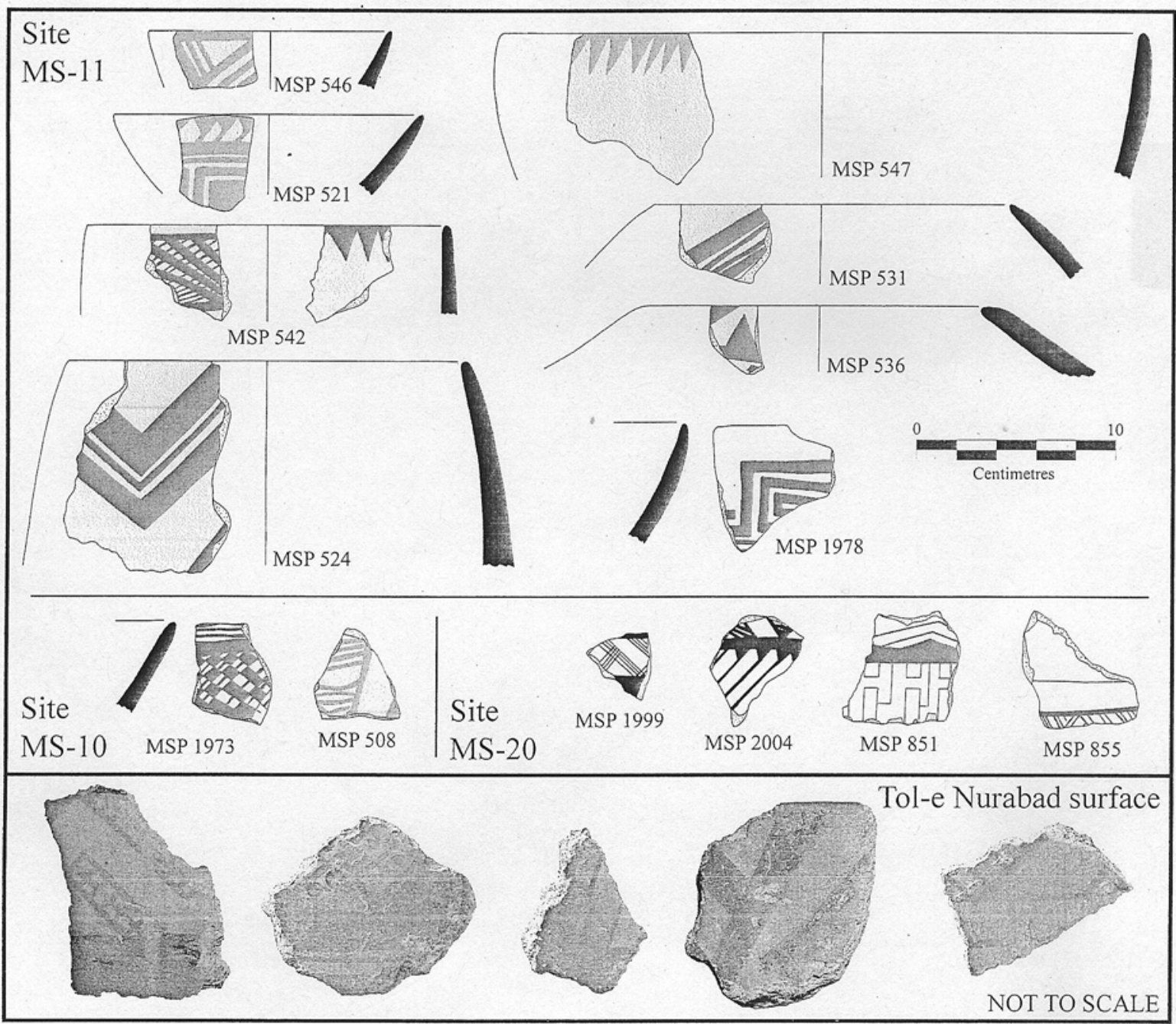

Fig. 10. Neolithic painted pottery from survey sites of Tappeh Jovi Khanimeh (MS-10), Tappeh Zurband (MS-11) and Tappeh Molla Shamshiri (MS-20) in the Dasht-e Rostam-e Do, Mamasani District, and from surface collection at Tol-e Nurabad.

means that the reconstruction of local ceramic sequences and regional inter-relationships for the middle and later Neolithic periods is a difficult process. The proliferation of regional ceramic industries across Neolithic Fars is perhaps indicated even by the material from within our own survey area in Mamasani. It is interesting to note that most of the painted Neolithic ceramics from Tol-e Nurabad and from MS-10, 11, and 20 are stylistically distinctive. As the Neolithic sites in the Dasht-e Rostam-e Do are more than $30 \mathrm{~km}$. overland from Tol-e Nurabad, the possibility that they represent a distinct sub-regional decorative tradition centred on the valleys to the north of the Dasht-e Nurabad cannot be ruled out. ${ }^{\prime \prime}$
Finally, it is interesting to note the ways in which our new ceramic assemblages from Tol-e Nurabad challenge the traditional conception of the progression of ceramic styles in later Neolithic Fars. Firstly, whilst Shamsabad period assemblages from the Kur River Basin are generally characterised as comprising only undecorated plain wares, it is clear that the latest Neolithic deposits in Mamasani include a substantial component of painted pottery. Secondly, undecorated soft ware ceramics are found throughout the Neolithic sequence at Tol-e Nurabad, alongside painted wares (see Fig. 8). Thus, in the future Shamsabad period sites in Mamasani will most likely be recognised not by their plain wares (as in the Kur River Basin), but by the presence of the specific 
painted ceramic styles that characterise the late Neolithic period in the area.

\section{Absolute chronologies for Neolithic Furs}

One of the clearest points to emerge from the discussion of variations in ceramic assemblages across the different valleys of Fars is the need for ceramic chronologies to be based upon a solid foundation of absolute radiometric dates. The calibrated radiocarbon dates obtained from Phases A27-A19 at Tol-e Nurabad are presented in graphical form in Figure 11. These dates have proven critical for the development of a provisional summary table of the absolute ceramic chronology of Neolithic Fars, which is presented in Figure 12. These figures require some preliminary explanation and comment before they are discussed in detail. Firstly, the absolute date ranges presented in Figures 11 and 12 reflect the ability of the $\mathrm{OxCal}$ calibration program to incorporate stratigraphic information into a Bayesian analysis of the radiocarbon dates from Tol-e Nurabad, effectively reducing the span of their calibrated age ranges (Bronk Ramsey 1995, 2001). Secondly, the reconstructed chronology of Figure 12 favours excavated assemblages and sequences, even where stratigraphic inferences are difficult to make. As a result, surface assemblages from sites such as Kushk-e Hezar (Alden et al. 2004), although potentially of great chronological significance, are shown in their likely chronological position on the right hand column of the chart but are not incorporated into the chronology shown in the other columns of the chart. Thirdly, it is recognised that excavated sequences that have been used to define a particular chronological period might not necessarily be occupied throughout the span of that period (e.g. Tall-i Mushki Levels I-V, which define the Mushki period in Figure 12, might only date to a small part of the Mushki period). This is difficult to represent graphically in the limited space on Figure 12, and as a result the period boundaries around these assemblages have generally been drawn to coincide with the chronological boundaries they stand for.

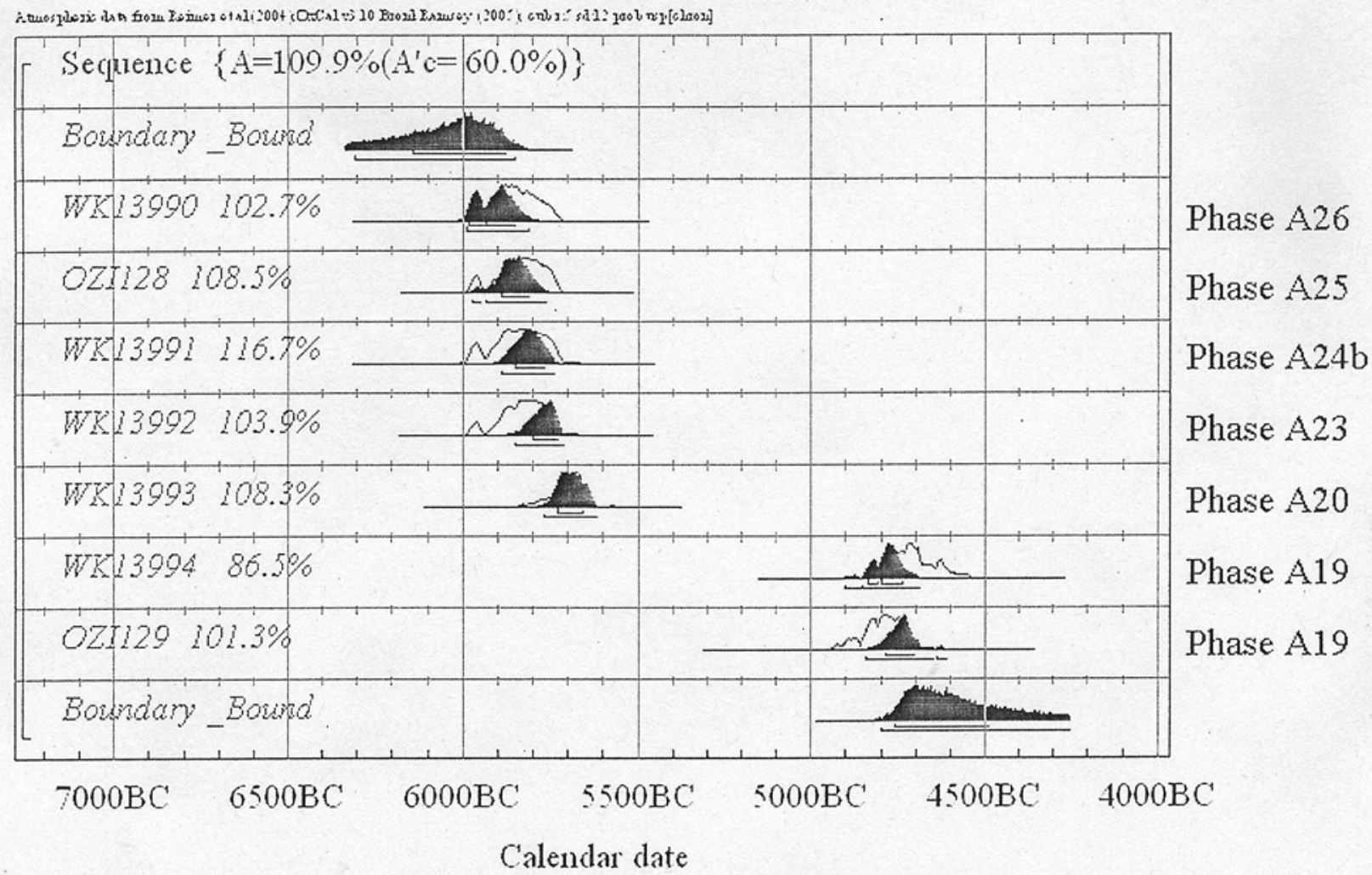

Fig. 11. Radiocarbon dates for charcoal samples from Neolithic phases at Tol-e Nurabad, showing prior (outline) and posterior (shaded) calibrated age ranges incorporating stratigraphic information. Calibrations and Bayesian statistical analyses were undertaken with OxCal version 3.10 (Bronk Ramsey 1995, 2001). 


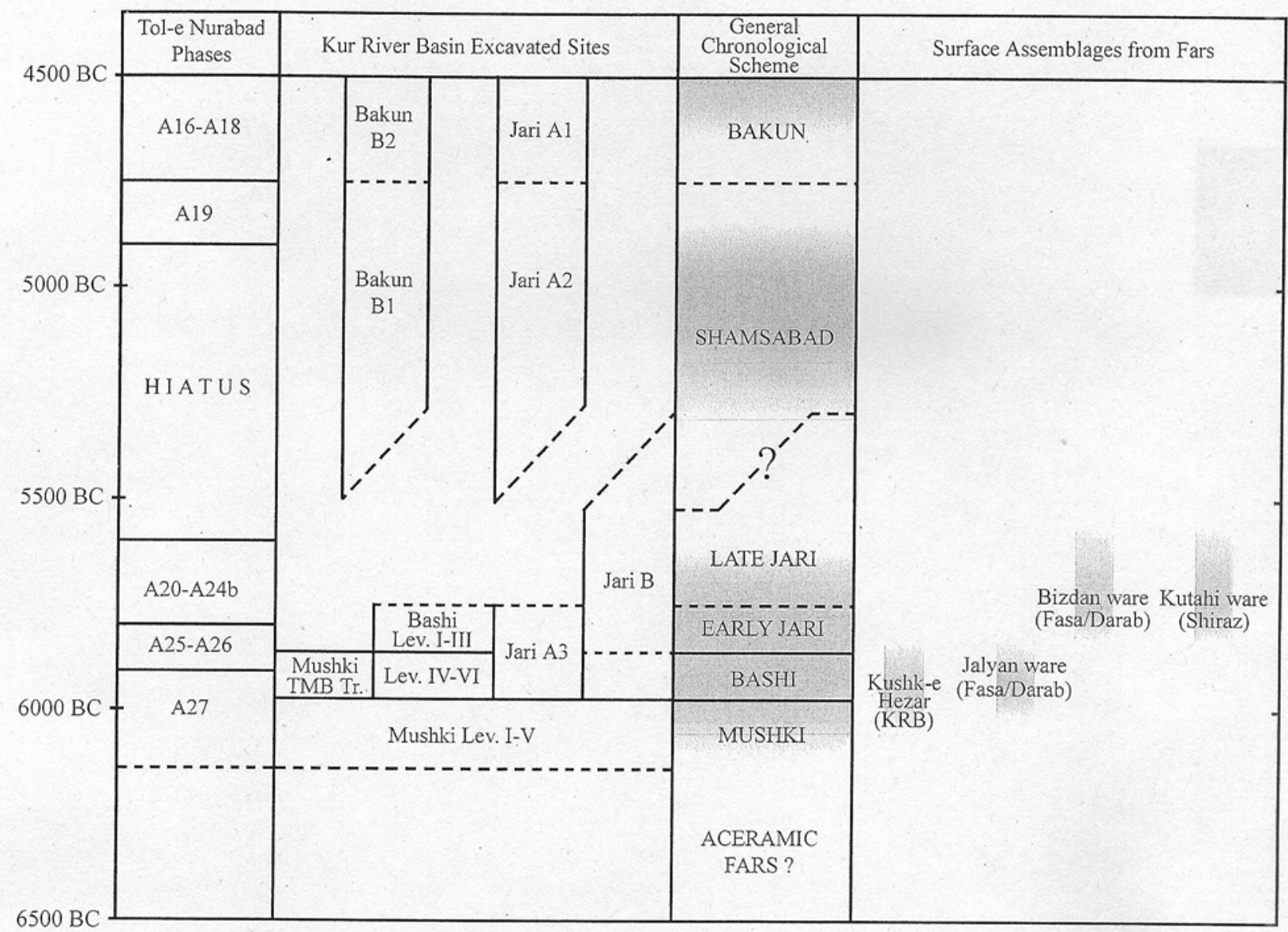

Fig. 12. A proposed absolute chronology for Neolithic Fars, divided by site and region. Uncertain chronological boundaries are indicated by dashed lines and/or by the use of graded shading to indicate the possible range of absolute dates within which a ceramic assemblage may have appeared. The general chronological terminology used in this article is represented by the grey-shaded central column.

Finally, both Figure 12 and the following discussion are based upon the assumption that the dates for the appearance of particular ceramic assemblages at Tol-e Nurabad are a good guide to the timing of their appearance at other sites across Fars. Of course, it is possible to imagine exceptions to this assumption, but until a wider array of absolute dates are available for ceramic assemblages from all the regions of Fars, the issue of time-depth in the spread of specific Neolithic ceramic styles cannot be addressed satisfactorily.

Turning to the radiocarbon dates from Tol-e Nurabad, it is unfortunate that the one analysed sample from Phase A27 is contaminated, dating well after the very reliable sequence of dates from later deposits at the site (see Fig. 5). Nevertheless, the series of dates from Tol-e Nurabad Phases A26-A20 (Fig. 11) and from excavations of Bashi assemblages at Toll-e Bashi
(S. Pollock pers. comm.) provide a clear terminus ante quem for the use of Mushki ceramics in Fars, indicating that the Mushki period should date to the very beginning of the 6th millennium B.C. and most probably back into the later 7 th millennium B.C. Unfortunately, we have no absolute dates for the beginning of the Mushki period from any site in Fars.

The deposits of Phase A26 at Tol-e Nurabad and the related ceramic assemblage, which bears some parallels to the Bashi period in the Kur River Basin, can be dated to the early 6 th millennium, c. 5900 B.C. These deposits are followed relatively quickly by phase A25, which contains a small proportion of early Jari style pottery; and by phases A24b-A20, which show the development of both stylistic elements related to the early Jari style and the florescence of a distinctive regional painted ceramic style. These developments can be placed in the 
period c. $59 / 5800-5600$ B.C. by the radiocarbon dates from Tol-e Nurabad.

We still lack, however, good absolute dates for the end of the Jari Period (i.e. also the beginning of the Shamsabad period) in the Kur River Basin, a fact which can be clearly seen in the disagreements between the various ceramic chronologies recently proposed for the area (e.g. Alden et al. 2004; Nishiaki 2003). Unfortunately, our new excavations in Mamasani have not exposed archaeological deposits of relevance to this issue. Given the current radiocarbon evidence, the Shamsabad period could begin as early as $56 / 5500$ B.C. or as late as $52 / 5100$ B.C. 12 The end of the Shamsabad period is somewhat easier to define. Two radiocarbon determinations from the latest Neolithic phase at Tol-e Nurabad (Phase A19) fall into the early 5th millennium B.C., c. $4850-4700$ B.C. The implications of these dates are clear, for whilst the Phase A19 deposits at Tol-e Nurabad include painted soft ware pottery, the majority of the assemblage consists of undecorated chafftempered soft wares directly comparable to Shamsabad ware from the Kur River Basin (see Fig. 8). The upper deposits of Phase A19 also produced a handful of blackon-buff painted Bakun style ceramic sherds (Weeks et al. in press: fig. 3.80 ), indicating that these levels date to the very end of the Neolithic period. A terminus ante quem for the Phase A19 deposits is provided by a radiocarbon date of c. $4780-4490$ B.C. ( $2 \sigma$ calibrated range) from a later deposit at the site (Phase A16) that is characterised by the exclusive use of painted black-onbuff (Middle) Bakun pottery.

\section{SOME THOUGHTS ON MAMASANI IN ITS WIDER NEOLITHIC CONTEXT}

The new radiocarbon dates from Tol-e Nurabad and elsewhere have certainly improved our understanding of the chronology of Neolithic Fars. Nonetheless, the provisional summary presented in Figure 12 indicates how much work remains to be done to clarify the relative and absolute chronology of the earliest settled communities of the region. For example, the start of the Mushki period, the end of the Jari period, and the duration of the Mushki, late Jari, and Shamsabad periods all remain highly uncertain. Moreover, the wellattested regional painted ceramic styles of Neolithic Fars found outside the Kur River Basin, such as the Jalyan and Bizdan wares of Fasa and Darab in southern
Fars, Kutahi wares from the Shiraz/Sarvestan region, and the pottery from Kavar in the Qara Aghaj valley remain almost entirely without a solid chronological footing. In many ways, we have added little to Sumner's important discussion of the Neolithic settlement of Fars written almost 30 years ago (Sumner 1977).

Nevertheless, the reformulated chronological periodisation proposed above, and the recently recovered material remains from Mamasani and the Kur River Basin, encourage the reconsideration of a number of issues related to the Neolithic communities of highland SW Iran. As a reflection of the debt owed to the research of William Sumner, three of the issues raised below derive explicitly from his 1977 overview of Neolithic Fars. These include thoughts on the mechanisms and rates of cultural development in highland SW Iran, indicators of interaction and integration within Neolithic Fars, and the possible colonisation of the region in the Neolithic period. Finally, the new chronological framework allows a more accurate placement of the Fars Neolithic sequence within wider developments across Neolithic Iran, with consequent implications for our understanding of Neolithic origins and expansion on a broad geographical scale. Whilst the extremely limited amount of supporting evidence available from Fars might suggest that our discussion of such broad issues is somewhat premature, by raising such matters we hope to highlight the factors that will play a critical role in our understanding of the Neolithisation of highland SW Iran and encourage research aimed at collecting data relevant to these issues.

\section{Settlement trajectories and the pace of cultural change}

Uncertainties regarding the duration of specific Neolithic periods have significant implications for our understanding of cultural developments in the Kur River Basin and more widely in Fars. The new radiocarbon dates from Tol-e Nurabad, if taken as representative of the region as a whole, suggest that the known decorated ceramic styles and assemblages of Fars (i.e. Mushki, Bashi and Jari) may have developed over a relatively short period of time in the late 7 th millennium and the first half of the 6th millennium B.C. As a consequence of compressing this part of the absolute chronological sequence, we are faced with the possibility of an exceedingly long Shamsabad period, stretching from 
perhaps 5500 B.C. or even a century earlier to as late as c. 4700 B.C. This is a significantly longer time span than that proposed by either Nishiaki (2003) or Alden et al. (2004), who both suggest a relatively short Shamsabad period of c. 200-300 years' duration, situated entirely within the early-mid 5th millennium B.C. ${ }^{13}$

The possibility of a 700 or 800 year duration for the Shamsabad period has significant implications for our understanding of the density of settlement in the region and the trajectory of Neolithic settlement expansion immediately preceding the Bakun period. Sumner (1977: 303) has suggested that the widespread appearance of Shamsabad pottery in the Kur River Basin might represent "the first step in the creation of a new cultural unity" in Fars, and should thus be regarded as an important precursor to the developments in socioeconomic complexity and cultural interaction/integration witnessed in the subsequent Bakun Period (see also Sumner 1994: 59). However, our understanding of the social phenomena underlying the origins of the Bakun period must undoubtedly be affected by the possibility that this "step" could in fact have been a long and slow process of development. At the most basic level, the settlement pattern in the Kur River Basin comprising 108 Shamsabad period sites (Sumner 1994: tab. 1) must be regarded differently if those sites represent the combined human settlement of the region over 800 years as opposed to 200 years. Moreover, the presence of painted ceramics contemporary with plain "Shamsabad" pottery at Tol-e Nurabad hints at a continued degree of regionalisation in the ceramic traditions of late Neolithic Fars. The new material from Mamasani thus highlights an element of diversity in material culture not previously recognised for late Neolithic Fars, and must significantly affect our perception of the Shamsabad period as precursor of (or step towards) cultural unity.

Likewise, the possibility of a relatively abrupt replacement and regional diversification of decorated ceramics in the Mushki, Bashi and Jari periods affects our understanding of the Neolithic people and communities who produced them. The survey data from the Kur River Basin and elsewhere (Sumner 1994: tab. 1) might now be interpreted as indicating a period of small-scale initial settlement in the Mushki period followed by relatively rapid growth through the Jari period (whose 50 recorded sites in the Kur River Basin can now possibly be compressed into perhaps 300 years), followed by a long period of slow growth represented by the Shamsabad period. Needless to say, such hypotheses will sink or swim based upon the absolute dating evidence that is eventually assembled for the Jari and Shamsabad periods in the Kur River Basin and wider Fars. At this point we wish only to emphasise that our provisional new chronology has implications for the understanding of some of the most basic cultural developments in Neolithic Fars.

\section{Isolation and integration in Neolithic Fars}

In his review of the evidence for Neolithic settlement in Fars, Sumner (1977: 303) suggested that "the presence of Jari, Kutahi, Bizdan, and possibly local styles in Kazerun and Sarvestan implies a degree of cultural isolation in the plains of the valleys of Fars" at the time these wares were produced and used. Sumner's proposal was based on the notion that isolation led to the development of unique regional ceramic styles through processes of independent indigenous stylistic development, and is a clear manifestation of the "interaction theory" of stylistic analysis (David and Kramer 2001: 168; Jones 1997: 115). In the following section we consider the data that can be assembled in order to investigate this hypothesis, and highlight alternative theoretical approaches which stress the active role of material culture in constructing and expressing cultural identity. Together, these approaches suggest the possibility of different understandings of the Neolithic ceramics of Fars as indicators of cultural interaction.

In the first instance, a variety of archaeological evidence allows us to question the concept of cultural isolation in Neolithic Fars. For example, a range of materials that are widely distributed at Neolithic sites in Fars are clearly not indigenous to the areas in which they are found, or indeed to Fars province. These include raw and semi-processed materials such as obsidian, marine shell, bitumen, and even copper, which are recorded in small quantities from as early as the Mushki period (e.g. Fukai et al. 1973: 37, 67-68; Alden et al. 2004: 38, tab. 5 , and fig. 9.3). Such raw materials attest to the possibility of contacts, perhaps indirect, with regions as widely separated as the Persian Gulf (shell), the Iranian Plateau (copper), eastern Anatolia (obsidian), and perhaps lowland Khuzistan or southern Mesopotamia (bitumen), in addition to the exchange relationships that distributed them within Fars. Other items of material culture, in particular smallfinds such as "labrets", are also found at widely separated sites across Fars and 
neighbouring regions of Iran that are otherwise characterised by distinctive ceramic assemblages (e.g. Tall-i Mushki, [Fukai et al. 1973: 57-64, pls. XV, LIV]; Toll-e Bashi [Bernbeck et al. 2003], Tol-e Nurabad [Weeks et al. in press: fig. 3.189], and at Kanakan A in Fasa [Dittmann 1986: 339 and fig. 2.10-13]; see also Kozlowski and Aurenche 2005: maps 7.9-10). Additionally, the shared technological traditions of ceramic manufacture across Neolithic Fars might well be regarded as an indicator of continued regional interaction. In short, although the fact that ceramics are painted in varied and distinctive ways across Neolithic Fars might be construed as an indication of the relative isolation and lack of interaction between their producers, other categories of material culture attest to interaction between the valleys of Fars and with neighbouring regions.

Additional arguments against isolation are provided by the consideration of settlement density data and subsistence practices. For example, survey evidence from the Kur River Basin suggests a steadily increasing settlement density throughout the Neolithic period (Sumner 1994: 48 and tab. 1). It seems counter-intuitive that groups became more isolated when both the number of settlements and the total human population of the region were growing. Moreover, when considering subsistence regimes of these Neolithic communities, the role played by seasonal mobility, herding, and hunting/foraging practices in the generation of opportunities for inter-community interaction should also be considered. From currently available evidence, it appears that Neolithic adaptations in highland Iran have generally incorporated some element of mobility, a development thought to have been favoured by the mountainous topography and highly seasonal climate of the Zagros (Hole 1998: 88). For example, Hole (1998: 85) has suggested that "the initial penetration of the Zagros was by herding people who carried agriculture with them seasonally to their summer pastures and then to their winter camps below the tree zone in the Fertile Crescent". Bernbeck's (2001: 8-10) discussion of Neolithic communities in the central Zagros, moreover, highlights the continued use of seasonally-occupied sites (and the importance of hunting) throughout the Neolithic period. In addition, a form of distant villagebased herding or fallow herding ${ }^{14}$ has been suggested to have existed in lowland SW Iran already by the 7th millennium B.C., as indicated by faunal and architectural evidence from the site of Tepe Tula'i (Bernbeck 1992;
Pires-Ferreira 1977; Hole 1974, 2004). Seasonal mobility, herding and hunting would have broadened the geographical range exploited by individuals and groups, which would inevitably have increased the possibilities for contact and interaction between communities across quite widely separated regions..$^{15}$ In such a context, it is difficult to imagine prolonged periods of cultural isolation for the different valley systems of Neolithic Fars, even without recourse to the raw material and artefactual evidence for interaction outlined above. Unfortunately, as yet we lack the basic knowledge on subsistence regimes in the region that will be critical in the development of such debates. ${ }^{16}$

Rather than seeing cultural contacts within Neolithic Fars as purely a by-product of raw material exchange relationships or of aspects of animal husbandry regimes, there may well have been other reasons for the maintenance of inter-community relationships. Specifically, it is interesting to consider matters of settlement density, demography and long-term group viability in relation to the isolation and integration of Neolithic Fars. As population numbers in Fars were low in the early Neolithic period, ${ }^{17}$ the maintenance of regional contacts within Fars might have been essential in the support of group biological viability. Frank Hole (1987b: 83), for example, has suggested that a population of around 500 people was necessary for a community to remain demographically viable in the long term. As villages of the Neolithic period in highland Iran almost invariably had populations much smaller than this (Sumner [1994: 52], for example, suggests common village populations in the Kur River Basin of well under 200 people), then the imperative of maintaining group biological viability may have fostered social interactions between communities in the search for suitable marriage partners.

Such perspectives may be important for understanding the geographic distribution of ceramic styles in Neolithic Fars, as exogamy and associated postmarriage residence rules could have supported the transmission of a significant amount of cultural and technological knowledge and the sharing of material culture between communities. In this formulation, the sparseness and small populations of Mushki period settlements in Fars could explain the relatively widespread distribution of Mushki pottery across the region. That is, interregional contacts may have been maintained in order to guarantee the availability of suitable marriage partners and thus the long-term 
survival and the small and widely scattered Mushki communities. Marriage alliances would have resulted in the movement of people from one area of Fars to another, and through them the possible spread of ceramic technology and styles.

Following from this suggestion, it might further be imagined that the regionalisation of decorated ceramic styles in Fars contemporary with the later Jari period represents the period when populations within individual valleys or valley systems of Fars rose to such an extent that viable communities could exist without recourse to exogamous marriage alliances with groups outside the valley system itself. 18 It is perhaps worthwhile noting in this context that Hole (1987b: 83) regards the archaeological observation (initially made by P. Mortensen) of "clusters" of three or four Neolithic villages in individual valley systems of western Iran, as a reflection of this basic biological requirement of group sustainability. The formation of such settlement clusters may have substantially reduced the need for the development of extra-regional marriage alliances and thus limited the permanent movement of people, material culture, technology and knowledge between regions. In this theoretical framework, variations in ceramic styles may have arisen not through isolation (which is discounted by the other categories of material culture discussed above), but through the removal of the specific mechanism responsible for the diffusion of ceramic styles and techniques, i.e. the relocation of people that was facilitated by exogamous marriage alliances. ${ }^{19}$

However, it is difficult to demonstrate that such exogamous marriage alliances were really necessary to maintain group viability. In contrast to Hole's explanation, computer simulation modelling of small group demographics (Moore 2001) indicates that groups much smaller than 500 people can exist for very long periods of time, up to many centuries, without external genetic input. ${ }^{20}$ Nevertheless, these studies highlight the tenuous and fragile nature of such small isolated communities, and the important contribution to group stability that is made by the possibility of obtaining marriage partners from even one other group (Moore 2001: 404-5, tab. 8). Overall, the data from such studies significantly complicate arguments about group interaction, site clusters, and long-term settlement viability in Neolithic Fars. They raise the possibility that the distribution of Neolithic sites and the regionalisation of ceramic assemblages might equally be explained by recourse to economic, technological, social, or ideological variables as by the needs of biological sustainability.

A final approach to conceptualising issues of cultural interaction in Neolithic Fars relies upon considering material items as makers, rather than just markers, of culture: Hodder's (1982) "symbols in action". In stressing the active construction of social identity through material culture, a number of archaeological and ethnographic studies have investigated the role of artefact style in communicating social messages (e.g. Wobst 1977; summarised in David and Kramer 2001: $168 \mathrm{ff}$.), especially the signalling of boundaries between social groups. In contrast to the "interaction theory" approach to stylistic variation used by William Sumner, who sees diversity arising from isolation, these different conceptions of "style" suggest that there is no strict relationship connecting the degree of interaction between groups and similarities in their material culture assemblages (Jones 1997: 115). In such a conceptual framework, cultural diversity can theoretically arise not only through isolation, but through increased interaction between groups (e.g. Hodder 1982: 58).

It is possible, therefore, that rather than representing cultural isolation and independent development, the various regional painted pottery styles of Neolithic Fars could feasibly have developed indigenously in the face of intensified regional contact, as manifestations of the desire to encode and broadcast (either within or between groups) social messages of group identity. The use of material culture items to transmit such information requires that objects are highly visible, used by members of more than one social group, and "used frequently and predictably in situations in which there is interaction between members of these different social groups" (Pollock 1983: 360, my emphasis). For example, ceramic forms used for serving and eating food can be prominent in certain social contexts and are thus ideally suited for the display of social messages through stylistic variation. A consideration of the typology and decoration of vessels from early Neolithic (i.e. pre-Shamsabad) Fars suggests that these vessels had a role in serving and eating food. Moreover, the size of some of the larger vessels suggests that communal eating may well have been commonplace in Neolithic Fars-although whether this represents gatherings larger than the family unit is not yet known. In such a visible context, the elaborately decorated pottery vessels of the Mushki, Bashi and Jari periods in Fars may have 
been useful and appropriate media for the transmission of messages about group identity.

Of course, our reconsideration of the interaction hypotheses proposed by Sumner benefits from the ability to apply archaeological theories that have only been elaborated and adopted in the 30 years since his overview of Neolithic Fars. ${ }^{21}$ Such theories provide a convincing and fundamental riposte to earlier uses of stylistic analysis for the assessment of group interactions in archaeology, and challenge our understanding of highland SW Iran in the Neolithic period. Moreover, they provide us with ways of explaining and reconciling aspects of the material record (i.e. diverse ceramic styles and evidence for interaction through exchange relationships) that appear contradictory under more traditional interpretations of the evidence, without resorting to the creation of "cultures" from our fragmentary and disparate assemblages of material remains (cf. Jones 1987: 106-27).

\section{The Neolithic "colonisation" of Fars and wider Iran}

In the absence of clear evidence for aceramic Neolithic occupation in Fars, we are left with the strong possibility that the Mushki period represents the material footprint of the Neolithic colonisation of Fars after a gap in human settlement of thousands of years. William Sumner's (1977: 303) discussion of this issue was typically nuanced: recognising that the external ceramic parallels for Mushki pottery were very limited, he suggested that colonisation of Fars in the Mushki period need only have represented a population movement from within one of the valleys of Fars itself to other areas of the province. This proposal allowed for the indigenous development of Mushki period ceramics somewhere in Fars (perhaps inspired by neighbouring pottery-using groups), and left open the issue of whether the Mushki period sites were in fact the first Neolithic settlements in the region. Significantly, even if an aceramic Neolithic occupation of Fars is eventually recognised archaeologically, we will still be confronted by a series of newly-established settlements requiring recourse to processes of migration and colonisation in order to be adequately understood. ${ }^{22}$

A discussion of the arrival of the first Neolithic communities in Fars raises a series of (as yet unanswered) questions regarding the mechanisms by which human groups moved into the region. For example, was colonisation and expansion a by-product of the mobility that seems to characterise elements of Neolithic communities in Iran? Hole (1987a: 54), for instance, regards aspects of Mushki settlement and material culture as indicative of mobile groups seasonally exploiting pastures in highland Fars, rather than the presence of permanent villages based upon dry farming. ${ }^{23}$ As yet, however, we have no evidence for the permanence or otherwise of Mushki period sites in Fars that might help us to distinguish between these possibilities. It is apparent that a great deal more archaeozoological and palaeobotanical evidence will be required before we have a good understanding of the subsistence practices and seasonality of occupation at Mushki period communities.

If the Mushki period does indeed represent the colonisation of Fars by food producing groups, whether sedentary or mobile, it is interesting to consider the factors that lead to the utilisation of the highland valleys of the region at this time. Aceramic Neolithic settlements dating to the 8 th millennium B.C. have been recorded at a number of sites in the central western Zagros and Zagros piedmont (see Fig. 1), such as Ganj Dareh, Tepe Abdul Hossein, Jarmo and Tepe Guran, and in the lowlands at Ali Kosh in Deh Luran and at Chogha Bonut in Susiana (Zeder and Hesse 2000; Pullar 1990; Braidwood and Howe 1960; Smith 1976; Meldgaard et al. 1963; Hole 1994, 2000; Hole et al. 1969; Alizadeh 2003b). Moreover, these regions witness occupation in the ceramic Neolithic period that appears to be substantially older than the Mushki period in Fars. Relevant sites include Jarmo, Guran, Sarab, Ali Kosh, Chogha Bonut and Chogha Mish (Kantor 1976; Delougaz and Kantor 1996), which date to the late 8th or first half of the 7th millennium B.C. (radiocarbon dates in Zeder and Hesse 2000; Voigt and Dyson 1992: tab. 2; see also Aurenche et al. 2001). In addition to these "Zagros Group" and lowland traditions (cf. Mortensen 1964; Kozlowski and Aurenche 2005: 32-34), ceramic Neolithic traditions that are most likely earlier than the Mushki period have been traced as far south-east as the Bakhtiari Mountains at Qale Rostam period I (Bernbeck 1989; Zagarell 1982; Nissen and Zagarell 1976). In comparison to these settlements, the earliest Neolithic sites in Fars seem a relatively late phenomenon.

A proper understanding of this issue may be dependent upon analysing the evidence from Neolithic Fars from a broader perspective. Significantly, the new absolute dates from Mamasani and the Kur River Basin 
have pushed the Neolithic settlement of the region back into the later 7th millennium B.C., meaning that the foundation of Mushki period sites in Fars is now broadly contemporary with the expansion of Neolithic communities across northern Iran as observed in the Urmia Basin at Hajji Firuz Tepe (Voigt 1983), in the Qazvin Plain at Cheshme Ali and Tepe Zagheh (Fazeli et al. 2005), in Semnan province at Sang-e Chaqmak (Masuda 1974, 1976), and as far to the east as Jeitun, situated beyond the Kopet Dagh mountains in Central Asia (Harris and Gosden 1996). The new dates from Mamasani undoubtedly raise the issue of whether the first Neolithic communities in Fars can be seen as part of this wider phenomenon of Neolithic expansion into and across the Iranian Plateau, some components of which have been regarded as clear archaeological instances of migration and colonisation (e.g. Harris 1998; Harris and Gosden 1996). ${ }^{24}$

Is there a southern "lobe" of this expansion, represented by Mushki and Jalyan sites in Fars, by the potentially 6th millennium Neolithic sites of Tepe Gaz Tavila and Tepe Yahya VII in Kerman (Beale 1986; Prickett 1986) and perhaps by a site as far to the east as Neolithic Mehrgarh (Jarrige and Jarrige 2006; Meadow 1996)? Frank Hole (1994: 107), for example, has suggested that food producing communities spread slowly from the central Zagros south into the Bakhtiari region and beyond. Consideration of this issue is complicated by the very limited amount of evidence available from excavated Neolithic sites in Iran outside of the SW lowlands and the central western Zagros. Moreover, the appearance of apparently aceramic Neolithic sites such as Sang-e Chaqmak West and Mehrgarh Period I near to the distal ends of these site distributions, not to mention their uncertain absolute dates, further complicates the notion of a widespread and rapid eastern expansion of farming groups with a developed agro-pastoral subsistence economy and ceramic technology (cf. Bernbeck et al. 2003: 76).

It is interesting to note, nevertheless, that the expansion of Neolithic communities in Iran outside the Central Western Zagros appears to be broadly contemporary with a conspicuous century-long period of climatic deterioration at c. 6200 B.C. (e.g. Alley et al. 1997; Rossignol-Strick 1999: 526; Byrd 2005; cf. Aurenche et al. 2001: 1198 and fig. 8). The correlation between settlement and palaeoclimatic data highlights the need for a better understanding of early-mid Holocene climate and environments in Fars, which are at the moment dependent upon data from sediment cores from the relatively distant locations of Lake Mirabad in Luristan and Lake Zeribar in Kurdistan (Wasylikowa 2005; Snyder et al. 2001; Stevens et al. 2001; ElMoslimany 1982; Van Zeist and Bottema 1977).

Whilst it is clear that the appearance of Neolithic communities in each of these various regions represent unique, historically contingent developments that cannot be adequately explained by recourse to a single cause, the possibility of investigating any shared elements of these transitions will be dependent upon examining Neolithisation processes in Iran at multiple geographical and archaeological scales of analysis. The geographic region discussed in this article, highland SW Iran, witnessed at least one such Neolithic transition, and fieldwork in the area is likely to provide important case studies of when, how, and why Neolithic ways of life spread east of the Fertile Crescent. With further fieldwork and analyses, it is hoped that the implications of our Mamasani material for an understanding of the Neolithisation of Fars and wider Iran will become apparent, and we will move beyond the phase of speculation.

\section{Notes}

1 The monograph-length publication of our initial research in the Mamasani District of Fars Province is currently in press (Potts and Roustaei, in press). Our field research in Mamasani was carried out under the auspices of a short term agreement between the Iranian Centre for Archaeological Research (ICAR) of the Iranian Cultural Heritage and Tourism Organisation (ICHTO) and the University of Sydney (USyd). This research would not have been possible without the support of Mr Seyed Mohammad Beheshti, Director General of the ICHTO, Mr Jalil Golshan, Deputy Director of the ICHTO, and Dr Massoud Azarnoush, the Director of the ICAR of the ICHTO. The field research in the Mamasani District was directed by Professor D.T. Potts (USyd) and Mr K. Roustaei (ICAR). The team members were: $\mathrm{Mr} \mathrm{K}$. Alamdari, Mr K. Alizadeh, Mr A. Khosrowzadeh, Mr A. Lashkari, Ms L. Niakan, Ms M. Seyedin (ICAR); Mr A. Asgari Chaverdi (ICHTO Shiraz Branch); Mr M. Zeidi (formerly of Tehran University); Ms B. McCall, Ms H.B. Potts and Ms S.C. Jackson (USyd); Dr C.A. Petrie (Cambridge University), and Dr L.R. Weeks (University of Nottingham). The project was made possible by research funding from the Australian Research Council, 
and financial and organisational support in Iran was provided by the ICAR and the ICHTO. The authors of this article would like to thank Professors Susan Pollock and Reinhard Bernbeck for sharing information on their recent excavations at Toll-e Bashi, and also the editors of Iran for the opportunity to publish this review and for their detailed comments on the draft version. Finally, the authors would like to thank the referees of this article, Dr John Alden, Prof. Reinhard Bernbeck, and Prof. William Sumner. Their insightful and constructive commentary helped to remove errors of fact, and provided a number of important insights that have been incorporated into the text as personal communications.

2 It should be noted here that, in his initial excavations in the region in the late 1920s, Herzfeld labelled the settlement of Tall-i Bakun A as "Neolithic", although it was soon thereafter recharacterised by Schmidt (1939: 121) as Copper Age. The Neolithic material from Stein's research has been systematically presented and discussed by $R$. Dittmann (1986: 343-66).

3 Although there is as yet no clear published evidence for aceramic Neolithic sites in the region, there have been a number of claims made for their existence. Three aceramic Neolithic sites were said to have been found by Vanden Berghe (mentioned in Sumner 1977), although they were not able to be found during resurvey of the Kur River Basin in the 1970s. However, recent evidence obtained during excavations in the Tang-e Bolaghi and nearby areas may support the idea of pre-Mushki aceramic Neolithic settlement in Fars. These include a cave occupation (Tsuneki and Zeidi in prep.) and the open air site of Tepe Rahmatabad, where excavation has revealed layers immediately beneath the dominant Bakun occupation at the site possibly indicative of aceramic Neolithic settlement (Hassan Fazeli, pers. comm.). However, none of this material has yet been closely examined.

4 The basic similarities between Mushki and Jari pottery from Fars and that from neighbouring regions are made apparent by reference to the so-called "Zagros group" ceramics, which have been described as displaying "covering motifs disposed in diagonals, and geometric motifs. The forms are often concave or keeled, without a neck or any kind of handle (occasionally lugs), with convex or flat bases" (Kozlowski and Aurenche 2005: 34). Aside from these general similarities, more specific stylistic parallels include examples of a motif from Tepe Guran Levels R-O (Meldgaard et al. 1963: fig. 15) and another from Qale Rostam period II (Zagarell 1982: fig. 9.1) that bear comparison to those seen at Tall-i Mushki on standard
Mushki pottery (esp. Fukai et al. 1973: pl. L patterns p23 and $\mathrm{p} 24)$.

5 As will be obvious, the chronology presented here is in disagreement with the wholesale reordering of the Neolithic relative chronology of Fars recently proposed by Abbas Alizadeh (2004), based upon his re-excavation of Tall-i Mushki, Tall-i Jari A and B, and Tall-i Bakun A and B. The detailed arguments against this reinterpretation have been presented elsewhere (Potts et al. in press: 14-15). However, in summary it seems that internal stylistic development of painted pottery motifs (e.g. Maeda 1986; Bernbeck et al. 2003), data on site numbers and settlement patterns in the Kur River Basin established by field survey (Sumner 1994: tab. 1), and the few identifiable external ceramic parallels for Mushki pottery (Voigt and Dyson 1992) support the relative ceramic chronology outlined here.

6 The discussion presented here is based upon the analysis of an assemblage of 466 registered sherds from Phases A19A27 at Tol-e Nurabad. These sherds represent all "diagnostics" (i.e. rims, bases, handles and decorated sherds) recovered during excavation. Of these 466 registered sherds, 71 come from Phaseș A27-A25, 327 come from Phases A24b-A20, and 58 come from Phase A19. Undecorated sherds comprise $25 \%$ of the registered assemblage from Phases A27-A25, 12\% from Phases A24b-A23, 35\% from Phases A22-A20, and 52\% from Phase A19, although numbers are not necessarily representative of overall assemblage composition as the definition of diagnostic sherds biases the registered assemblage against plain wares.

7 Defined here as that recovered from Tall-i Mushki Levels I-V during the University of Tokyo excavations (Fukai et al. 1973).

8 Defined here as that recovered from the lower levels of Talli Jari B (i.e. particularly material from trenches D, W, and Y characterised by pottery motif types a-e; see Maeda 1986: tabs. 1-6 and figs. 1-7) and Levels I-III of Toll-e Bashi (R. Bernbeck and S. Pollock, pers. comm. 2005).

9 Alternatively, the Tol-e Nurabad Jari sherds lack the thin white slip that seems to characterise much of the Jari pottery from the Kur River Basin (Bernbeck et al. 2003), which may indicate a local origin in Mamasani. However, it has been suggested that white slip is a late Jari phenomenon, and so the lack of white slipped Jari sherds at Tol-e Nurabad may simply reflect the fact that our deposits of Phases A26A25 are contemporary with the early Jari period (John Alden, pers. comm.).

10 The strong stylistic continuity that can be traced in specific motifs from the Mushki period through the Bashi period 
and into the Jari period, would perhaps best be indicated by a system of chronological terminology that groups these assemblages rather than divides them by labels. The system recently proposed by Abbas Alizadeh (2003b: 87), incorporating the designations "Archaic Fars 1, 2, etc." to describe the progression of painted pottery assemblages from Neolithic Fars, has merits in this respect, as does Frank Hole's (1987a: 30) proposed "Initial, Early, Middle, and Late Village Period" terminology. Unfortunately, both schemes mask the strong variability in contemporary Neolithic ceramic assemblages across Fars and wider Neolithic/Chalcolithic Iran which is the focus of this article. Thus, a more traditional chronological terminology based upon type sites and assemblages has been employed in the present publication (see Fig. 12 and discussion below).

11 Survey of Neolithic sites in the Dasht-e Nurabad itself, which has not yet been undertaken, will be critical in the resolution of this issue.

12 A date of $6264 \pm 70$ B.P. has been obtained from Tall-i Bakun B Shamsabad levels, which produces a 2-sigma calibrated range of 5380-5020 B.C. A second date of 5990 \pm 81 B.P. from Shamsabad levels at Tall-i Bakun B produces a 2-sigma calibrated range of 5250-4650 B.C. In determining the most likely range for the beginning of the Shamsabad period, it is clear that considerations of the time required for the development of specific ceramic styles are of little or no relevance. Thus, we do not need to postulate many centuries for the development of ceramic styles as recorded at Tall-i Jari B by Maeda (1986) and a consequently late start to the Shamsabad period. The plethora of ceramic styles known from the first half of the 6th millennium in Fars, for example, indicates that ceramic decorative styles were generally very short lived at this time. In fact, we can quite plausibly suggest a Shamsabad period beginning as early as 5500 B.C. and still allow several centuries for the developments in ceramic style seen at Tall-i Jari B, occupation of which probably begins c. 5800 B.C. Ceramic styles can theoretically change very quickly, very slowly or at any pace in between: the point is that absolute dates tell us about the pace of change in ceramic styles, not the other way around.

13 The absolute chronology for the Shamsabad period proposed here agrees very closely with that suggested by Hole (1987a: tab. 2), although we would stress the uncertainty regarding the absolute dates for the beginning of this period. The beginning of the Shamsabad period is also placed in the mid-6th millennium B.C. by Alizadeh in a recent publication (Alizadeh 2003a: tab. 3), although there the Bakun period is said to begin c. 5100 B.C., as opposed to the beginning date of $c$. $48 / 4700$ B.C. proposed here, so the Shamsabad period remains of relatively brief duration in Alizadeh's conception.

14 In which components of family/village herds were taken for periods of a few days to seasonally available pastures outside the day-to-day territory of the village (see Abdi 2003: 401 for a description and definition of this practice).

15 Another possibility is the existence of an independent fully mobile pastoralist component of the population in Fars at this time. However, this is difficult to imagine if only because of the obvious limitations placed on the development of fully mobile pastoralism by the ability to exploit secondary animal products such as wool and dairy products (for which we have little or no evidence in 6th millennium B.C. Fars).

16 The dearth of knowledge on this subject is indicated by the fact that the earliest quantified assemblage of faunal remains from Fars thus far published consists of a few hundred bones from the fifth millennium Bakun period site of Tall-i Gap (where wild species including deer and gazelle represented $75 \%$ of the identifiable bones, cattle $23 \%$, and sheep/goat only 2\%; Egami and Sono 1962: App. II). Evidence for earlier Neolithic animal exploitation in Fars is largely anecdotal. Hole (1987a: 54) reports seeing "quantities of sheep/goat bone and those of a large ungulate, probably Bos" during a visit to Tall-i Mushki during its excavation. The presence of capra and bos at Tall-i Mushki is noted also by Payne (1991: 139) in his study of the equid remains from the site, who also mentions the presence of onager and gazelle as well as rare sus bones and those of unspecified carnivores. The faunal and botanical samples from Tol-e Nurabad and Tol-e Spid are currently in the process of analysis, as are those from old and more recent excavations at Tall-i Mushki, Tall-i Jari A and B, and Tall-i Bakun (Marjan Mashkour, pers. comm.). The publication of these studies will revolutionise our understanding of animal exploitation in Neolithic and Chalcolithic Fars.

17 Only eight Mushki period sites are known from the Kur River Basin (Sumner 1994: tab. 1). Our research in Mamasani has thus far located only one site with certain Mushki period occupation (i.e. Tol-e Nurabad), although some carinated soft-ware ceramic vessel forms from survey in the Dasht-e Rostam-e Do may represent Mushki or Mushki-related material (see Zeidi et al. in press).

18 In essence, population in the valleys at this time could have functioned as the equivalent of the "maximum band" defined by Wobst (1974: 151-52). In this formulation, "minimum bands" represent the most permanent and 
strongly integrated social unit in the society, and are large enough to survive prolonged periods in isolation through co-operation, division of labour and food sharing. The "maximum band", in contrast, might be only vaguely or loosely conceived of as a social unit by its members, but its membership nevertheless constitutes a marriage network critical for maintaining the long-term viability of its constituent minimum bands.

19 If such is the case, it may well be fair to highlight the careful phrasing of Sumner's isolation hypothesis. The cessation of marriage relationships between more widely separated regions within Fars might well be regarded as representing "a degree of cultural isolation" (Sumner 1977: 303) in relation to earlier and later periods in Fars, even though groups maintained other linkages such as exchange relationships.

20 For example, starting groups of 60 persons used in the simulation models survived for c. 6-8 centuries on average, and even starting groups of as small as 20 people had an average time to extinction of more than three centuries (Moore 2001: tabs. 2-5). Admittedly, these simulations are based on forager groups rather than on agriculturalists.

21 See David and Kramer (2001: 168-224) for an overview of the development of this particular field of anthropological and archaeological theory.

22 There is substantial evidence for occupation in Fars (at least in the Kur River Basin) in the Epipalaeolithic period, where sites with lithic industries comparable to Zarzian industries known from the central western Zagros have been reported (Rosenberg 2003). Elsewhere, Zarzian sites seem to date exclusively to the late/terminal Pleistocene (Smith 1986), and such a date is assumed on typological grounds for the sites in the Kur River Basin. However, as there are no radiometric dates for these sites and many areas of Fars remain poorly known archaeologically, the possibility of long-lived remnant forager groups in early Holocene Fars cannot be entirely ruled out (cf. Hole 1994: 107).

23 Interestingly, there is a readily observable development in architectural styles from the lowest levels of Tall-i Mushki (Level V: Fukai et al. 1973: pl. XLV) to the upper levels (Levels II and I: Fukai et al. 1973: pls. XLIII, XLIV) which may be significant in understanding the issue of sedentary occupation at the site. Frank Hole's (1994) ethnographic study of nomadic pastoralist groups in modern day Iran suggests a number of architectural features that may distinguish tent dwellings (and their mobile occupants) from village houses and rooms (with their more sedentary occupants). Unfortunately, given the limited architectural exposures from Tall-i Mushki, it is difficult to apply Hole's observations to the evidence, although the cellular nature of the later Mushki Level I structures links them more closely to village house styles than to the modern rectilinear tent foundations recorded by Hole. The existence of multiroomed mudbrick and chineh architecture at sites like Tall-i Jari A Level III and Tall-i Jari B (Egami 1967; Egami et al. 1977) tentatively supports the notion of a more sedentary occupation in the region by the Bashi-early Jari period at the latest, although the interpretation of architectural remains as a priori evidence of sedentism has been questioned (Bailey and Whittle 2005: 2; see also Hole 2004: 67-68 for a brief discussion of the nature of sedentary and mobile use of settlement sites).

24 This view is tenuously supported by additional genetic and linguistic data (e.g. Quintana-Murci et al. 2001, 2004; Renfrew 1996).

\section{Bibliography}

Abdi, K. 2003. "The Early Development of Pastoralism in the Central Zagros Mountains", Journal of World Prehistory 17.4: 395-448.

- Pollock, S. and Bernbeck, R. 2003. "Fars Archaeology Project 2003: Excavations at Toll-e Bashi", Iran 41: 339-44.

Alden, J.R. 1979. Regional Economic Organisation in Banesh Period Iran. $\mathrm{PhD}$, University of Michigan, Ann Arbor.

- Abdi, K., Azadi, A., Biglari, F. and Heydari, S. 2004. "Kushk-e Hezar: A Mushki/Jari period site in the Kur River Basin, Fars, Iran", Iran 42: 25-45.

Alizadeh, A. 2003a. Excavations at the Prehistoric Mound of Chogha Bonut, Khuzestan, Iran: Seasons 1976/77, 1977/78, and 1996. Oriental Institute Publications Volume 120 , Oriental Institute of the University of Chicago, Chicago.

- 2003b. "Some Observations Based on the Nomadic Character of Fars Prehistoric Cultural Development", in Miller, N F. and Abdi, K. (eds.), Yeki bud, yeki nabud: Essays on the Archaeology of Iran in Honor of William M. Sumner. The Cotsen Institute of Archaeology, University of California, Los Angeles: 83-97.

- 2004. "Recent archaeological investigations on the Persepolis plain", The Oriental Institute News and Notes 183: 1-7.

Alley, R.B., Mayewski, P.A., Sowers, T., Stuiver, M., Taylor, K.C. and Clark, P.U. 1997. "Holocene climatic instability: a prominent, widespread event $8200 \mathrm{yr}$ ago", Geology 25.6: 483-86. 
Aurenche, O., Galet, P., Régaignon-Caroline, E. and Évin, J. 2001. "Proto-Neolithic and Neolithic cultures in the Middle East - the birth of agriculture, livestock raising, and ceramics: a calibrated $14 \mathrm{C}$ chronology 12,500-5500 cal B.C.", Radiocarbon 43/3: 1191-202.

Bailey, D. and Whittle, A. 2005. "Unsettling the Neolithic: breaking down concepts, boundaries, and origins", in Bailey et al. 2005: 1-7.

- Whittle, A. and Cummings, V. (eds.) 2005. (Un)settling the Neolithic. Oxford: Oxbow.

Beale, T.W. 1986. Excavations at Tepe Yahya, Iran 1967-1976: The Early Periods. American School of Prehistoric Research Bulletin, Volume 38, Peabody Museum of Archaeology and Ethnology, Cambridge.

Bernbeck, R. 1989. Die Neolithische Keramik aus Qale Rostam, Bakhtiyari-Gebiet (Iran): Klassifikation, Produktionsanalyse und Datierungspotential. Altertumswissenschaften 9, Schäuble Verlag, Berlin.

- 1992. "Migratory patterns in early nomadism: a reconsideration of Tepe Tula'i", Paleorient 18.1: 77-88.

- 2001. "Forschungsperspektiven für das Iranische Neolithikum", Archäologische Mitteilungen aus Iran und Turan 33: 1-18.

- Abdi, K., Gregg, M. and Heydari, S. 2005. "A Note on the Neolithic of the Qara Aghaj Valley, Fars Province", in Azarnoush, M. (ed.), Archaeological Reports of the Iranian Cultural Heritage Organization 4. Tehran: ICAR.

- Pollock, S. and Abdi, K. 2003. "Reconsidering the Neolithic at Toll-e Bashi (Iran)", Near Eastern Archaeology 66: 76-78.

Braidwood, R.J. and Howe, B. 1960. Prehistoric Investigations in Iraqi Kurdistan. Chicago: University of Chicago Press. The Oriental Institute of the University of Chicago Studies in Ancient Oriental Civilization No. 31.

Bronk Ramsey, C. 1995. "Radiocarbon calibration and analysis of stratigraphy: the OxCal program", Radiocarbon 37: 425-30.

- 2001. "Development of the Radiocarbon Program OxCal", Radiocarbon 43 (2A): 355-63.

Byrd, B.F. 2005. "Reassessing the Emergence of Village Life in the Near East", Journal of Archaeological Research 13: 231-90.

David, N. and Kramer, C. 2001. Ethnoarchaeology in Action. Cambridge: Cambridge University Press. Cambridge World Archaeology:

Delougaz, P. and Kantor, H.J. (eds.) 1996. Chogha Mish Volume 1: The First Five Seasons of Excavations 1961-1971. Oriental Institute Publications, 101, Oriental Institute, Chicago.
Dittmann, R. 1986. Betrachtungen zur Frühzeit des SüdwestIran. Teil 1. Regionale Entwicklungen vom 6. bis Frühen 3. Vorchristlichen Jahrtausend. Berlin: Dietrich Reimer Verlag. Berliner Beiträge zum Vorderen Orient Band 4.

Dyson, R.H. 1965. "Problems in the relative chronology of Iran, 6000-2000 B.C.", in Ehrich, R., Chronologies in Old World Archaeology. Chicago, University of Chicago Press: 215-65.

Edmonds, M. and Richards, C. (eds.) 1998. Understanding the Neolithic of North-Western Europe. Glasgow: Cruithne Press.

Egami, N. 1967. "Excavations at two prehistoric sites Tepe Djari A and B in the Marv-Dasht Basin", in Pope, A.U. (ed.), A Survey of Persian Art: from Prehistoric times to the Present, XIV. Oxford University Press, London: 2936-39.

Egami, N. and Masuda, S. 1962. Marv-Dasht I: The Excavation at Tal-i-Bakun 1956. Tokyo University IraqIran Archaeological Expedition Reports, 2, Institute of Oriental Culture of the University of Tokyo, Tokyo.

- Masuda, S. and Gotoh, T. 1977. "Tal-i Jarri A: A preliminary report of the excavations in Marv Dasht, 1961 and 1971", Orient 8: 1-14.

- and Sono, T. 1962. Marv-Dasht II: The Excavation at Talli-Gap 1959. Tokyo University Iraq-Iran Archaeological Expedition Reports, 3, Institute of Oriental Culture of the University of Tokyo, Tokyo.

El-Moslimany, A.P. 1982. "The Late Quaternary Vegetational History of the Zagros and Taurus Mountains in the regions of Lake Mirabad, Lake Zeribar and Lake Van-a reappraisal", in Bintliff, J.L. and Van Zeist, W. (eds.), Palaeoclimates, Palaeoenvironments and Human Communities in the Eastern Mediterranean Region in Later Prehistory, 133(i \& ii). BAR International Series, Oxford: $343-51$.

Fazeli, H., Wong. E.H. and Potts, D.T. 2005. "The Qazvin Plain revisited: a reappraisal of the chronology of northwestern central plateau, Iran, in the 6th to 4 th millennium B.C.", Ancient Near Eastern Studies 42: 3-82.

Fukai, S., Horiuchi, K. and Matsutani, T. 1973. Marv-Dasht III: The Excavation at Tall-i-Mushki 1965. Tokyo University Iraq-Iran Archaeological Expedition Reports, 14, Institute of Oriental Culture of the University of Tokyo, Tokyo.

Gotch, P. 1968. "A Survey of the Persepolis Plain and Shiraz Area", Iran 6: 168-70.

Harris. D.R. (ed.) 1996. The Origins and Spread of Agriculture and Pastoralism in Eurasia. UCL Press, London.

- 1998. "The Spread of Neolithic Agriculture from the Levant to Western Central Asia", in Damania, A.B. et al. (eds.), The 
origins of agriculture and crop domestication: proceedings of the Harlan Symposium. Aleppo, Syria: ICARDA.

— and Gosden, C. 1996. "The beginnings of agriculture in Central Asia", in Harris 1996: 370-89.

Hodder, I. 1982. Symbols in Action: Ethnoarchaeological Studies of Material Culture. Cambridge: Cambridge University Press.

- 1998. "The domus: some problems reconsidered", in Edmonds and Richards 1998: 84-101.

Hole, F. 1974. "Tepe Tūlā'î: an early campsite in Khuzistan, Iran", Paleorient 2/2: 219-37.

Hole, F. 1987a. "Archaeology of the Village Period", in Hole, F. (ed.), The Archaeology of Western Iran: Settlement and Society from Prehistory to the Islamic Conquest. Smithsonian Series in Archaeological Inquiry, Smithsonian Institution Press, Washington D.C.: 29-78.

- 1987b. "Settlement and Society in the Village Period", in Hole, F. (ed.), The Archaeology of Western Iran: Settlement and Society from Prehistory to the Islamic Conquest. Smithsonian Series in Archaeological Inquiry, Smithsonian Institution Press, Washington, D.C.: 79-105.

- 1994. "Interregional aspects of the Khuzestan AceramicEarly Pottery Neolithic", in Gebel, H. G. and Kozlowski, S.K. (eds.), Neolithic Chipped Stone Industries of the Fertile Crescent: Proceedings of the First Workshop on PPN Chipped Lithic Industries. Studies in early Near Eastern Production, Subsistence, and Environment 1, Ex Oriente, Berlin: 101-16.

- 1996. "The context of caprine domestication in the Zagros region", in Harris 1996: 263-81.

- 1998. "The Spread of Agriculture to the Eastern Arc of the Fertile Crescent: Food for the Herders". in Damania, A.B., Valkoun, J., Willcox, G. and Qualset, C.O. (eds.), The Origins of Agriculture and Crop Domestication: Proceedings of the Harlan Symposium, 10-14 May 1997, Aleppo, Syria. International Center for Agricultural Research in the Dry Areas, Aleppo: 83-92.

- 2000. "New radiocarbon dates for Ali Kosh, Iran", NeoLithics. 1: 13.

- 2004. "Campsites of the Seasonally Mobile in Western Iran", in Folsach, K.V., Thrane, H. and Thuesen, I. (eds.), From Handaxe to Khan: Essays Presented to Peder Mortensen on the Occasion of his 70th Birthday. Aarhus University Press, Aarhus: 67-85.

- Flannery, K.V. and Neely, J.A. 1969. Prehistory and Human Ecology of the Deh Luran Plain: An Early Village Sequence from Khuzistan, Iran. Memoirs of the Museum of Anthropology, University of Michigan, 1, Museum of Anthropology, University of Michigan, Ann Arbor.
Jarrige, J.-F. and Jarrige, C. 2006. "Premiers pasteurs et agriculteurs dans les sous-continent Indo-Pakistanais", C.R. Palevol 5: 463-72.

Jones, S. 1997. The Archaeology of Ethnicity. London: Routledge.

Kantor, H. 1976. "The Excavations at Choqa Mish, 1974-75", in Bagherzadeh, F. (ed.), Proceedings of the IVth Annual Symposium on Archaeological Research in Iran. Iranian Centre for Archaeological Research, Tehran: 23-41.

Kozlowski, S.K. and Aurenche, O. 2005. Territories, Boundaries and Cultures in the Neolithic Near East. Archaeopress: Oxford. BAR International Series 1362.

Maeda, A. 1986. "A study on the painted pottery from Tepe Djari B (in Japanese with English Summary)", Bulletin of the Ancient Orient Museum 8: 45-86.

Masuda, S. 1974. "Excavations at Tappeh Sang-e Chaxamaq", in Bagherzadeh, F. (ed.), Proceedings of the Second Annual Symposium on Archaeological Research in Iran. Tehran: ICAR: 23-33.

- 1976. "Report of the archaeological investigations at Šhahrud", in Bagherzadeh, F. (ed.), Proceedings of the Fourth Annual Symposium on Archaeological Research in Iran. Tehran: ICAR: 63-70.

Meadow, R.H. 1996. "The origins and spread of agriculture and pastoralism in northwest South Asia", in Harris 1996: $390-412$.

Meldgaard, J., Mortensen, P. and Thrane, H. 1963. "Excavations at Tepe Guran, Luristan", Acta Archaeologica 34: $97-133$.

Miroschedji, P. de. 1972. "Prospections Archéologiques dans les valées de Fasa et de Darab (rapport préliminaire)", in Bagherzadeh, F. (ed.), Proceedings of the 1st Annual Symposium on Archaeological Research in Iran. Iranian Centre for Archaeological Research, Tehran: 1-7.

Moore, J.H. 2001. "Evaluating Five Models of Human Colonisation", American Anthropologist 103.2: 395-408.

Mortensen, P. 1964. "Additional remarks on the chronology of early village farming communities in the Zagros area", Sumer 20: 28-36.

Nishiaki, Y. 2003. Catalogue of Archaeological Materials in the Department of Archaeology of Western Asia, Part 6: Prehistoric Pottery from the Marv Dasht Plain, Iran. Tokyo: University Museum, University of Tokyo. Material Reports No. 51.

Nissen, H.J. and Zagarell, A. 1976. "Expedition to the Zagros Mountains", in Bagherzadeh, F. (ed.), Proceedings of the IVth Annual Symposium on Archaeological Research in Iran, 1975. Iranian Centre for Archaeological Research, Tehran: 159-89. 
Payne, S. 1991. "Early Holocene Equids from Tall-i-Mushki (Iran) and Can Hassan III (Turkey)", in Meadow, R.H., and Uerpmann, H.-P. (eds.), Equids in the Ancient World: Volume II: 132-177. Wiesbaden.

Petrie, C.A., Asgari Chaverdi, A. and Seyedin, M. in press a. "Excavations at Tol-e Spid", in Potts and Roustaei in press.

Petrie, C.A., Weeks, L.R., Potts, D.T. and Roustaei, K. in press b. "Perspectives on the Cultural Sequence of Mamasani", in Potts and Roustaei in press.

Pires-Ferreira, J.W. 1977. "Tepe Tula'i: faunal remains from an early campsite in Khuzistan, Iran", Paleorient 3: 275-80.

Pluccienik. M. 1998. 'Deconstructing 'the Neolithic' in the Mesolithic-Neolithic transition", in Edmonds and Richards 1998: 61-83.

Pollock, S. 1983. "Style and information: an analysis of Susiana ceramics", Journal of Anthropological Archaeology 2: 354-90.

Potts, D.T. and Roustaei, K. (eds.) in press. The Mamasani Archaeological Project Stage One: A report on the first two seasons of the ICAR-University of Sydney expedition to the Mamasani District, Fars Province, Iran. Tehran: ICAR.

- Roustaei, K., Weeks, L.R. and Petrie, C.P. "The Mamasani District and the Archaeology of Southwestern Iran", in Potts and Roustaei in press.

Prickett, M. 1986. "Chapter 9. Settlement during the early periods" in Beale 1986: 215-43.

Pullar, J. 1990. Tepe Abdul Hosein: A Neolithic Site in Western Iran, Excavations 1978. BAR International Series, 563, British Archaeological Reports, Oxford.

Quintana-Murci, L., Krausz, C., Zerjal, T., et al. 2001. "Ychromosome lineages trace diffusion of people and languages in southwestern Asia", American Journal of Human Genetics 68: 537-42.

- Chaix, R., Wells, R.S., et al. 2004. "Where west meets east: The complex mtDNA landscape of the southwest and Central Asian corridor", American Journal of Human Genetics 74: 827-45.

Renfrew, C. 1996. "Language families and the spread of farming", in Harris 1996: 70-92.

Rosenberg, M. 2003. "The Epipaleolithic in the Marvdasht", in Miller, N.F. and Abdi, K. (eds.), Yeki bud, yeki nabud: Essays on the Archaeology of Iran in Honor of William M. Sumner. The Cotsen Institute of Archaeology, University of California, Los Angeles.

Rossignol-Strick, M. 1999. "The Holocene climatic optimum and pollen records of sapropel 1 in the eastern Mediterranean, 9000-6000 B.P.", Quaternary Science Reviews 18: 515-30.

Schmidt, E.F. 1937. "Tol-e-Bakun: Prehistoric mound near Persepolis", University of Pennsylvania Museum Bulletin 7.1: 27-28.

- 1939. "Tall-i Bakun", in The Treasury of Persepolis and Other Discoveries in the Homeland of the Achaemenians. Oriental Institute Communications No. 21, University of Chicago Press, Chicago: 121-29.
Smith, P.E.L. 1976. "Reflections on Four Seasons of Excavations at Tappeh Ganj Dareh", in Bagherzadeh, F. (ed.), Proceedings of the IVth Annual Symposium on Archaeological Research in Iran, 1975. Iranian Centre for Archaeological Research, Tehran: 11-22.

- 1986. Palaeolithic Archaeology in Iran. The American Institute of Iranian Studies Monographs, University Museum, University of Pennsylvania, Pennsylvania.

Snyder, J.A., Wasylik, K., Fritz, S.C., et al. 2001. "Diatombased conductivity reconstruction and palaeoclimatic interpretation of a 40-ka record from Lake Zeribar, Iran", Holocene 11: 737-45.

Stein, M.A. 1936. "An Archaeological Tour in the Ancient Persis", Iraq 3: 179-225.

Stevens, L.R., Wright, H.E. and Ito, E. 2001. "Proposed changes in seasonality of climate during the Lateglacial and Holocene at Lake Zeribar, Iran", Holocene 11: 747-55.

Stuckenrath, R. 1963. "University of Pennsylvania Radiocarbon Dates VI", Radiocarbon 5: 82-103.

- Coe, W.R. and Ralph, E.K. 1966. "University of Pennsylvania Radiocarbon Dates 9", Radiocarbon 8: 348ff.

Sumner, W.M. 1972. Cultural Development in the Kur River Basin, Iran: an archaeological analysis of settlement patterns. $\mathrm{PhD}$, Pennsylvania.

- 1977. "Early Settlements in Fars Province, Iran", in Levine, L.D. and Cuyler Young; T. Jr. (eds.), Mountains and Lowlands: Essays in the Archaeology of Greater Mesopotamia. Malibu: Undena: 291-305.

- 1980. Problems of large-scale, multi-disciplinary regional archaeological research: the Malyan project. A symposium presented at the annual meeting of the Society for American Archaeology, Philadelphia, May 1, 1980. Unpublished symposium handout package.

- 1990. "Full-Coverage Regional Archaeological Survey in the Near East: An Example from Iran", in Fish, S.K. and Kowalewski, S.A. (eds.), The Archaeology of Regions: A case for Full-Coverage Survey. Smithsonian Series in Archaeological Inquiry, Smithsonian Institution Press, Washington D.C.: 87-115.

- 1994. "The Evolution of Tribal Society in the Southern Zagros Mountains, Iran", in Stein, G. and Rothman, M.S. (eds.), Chiefdoms and Early States in the Near East: The Organizational Dynamics of Complexity. Prehistory Press: Madison Wisconsin: 47-65.

Thomas, J.S. 1991. Rethinking the Neolithic. Cambridge: Cambridge University Press.

Tsuneki, A. and Zeidi, M. in preparation. "Iran-Japan Archaeological Expedition to the Sivand Dam Salvage Area, 2005", Tang-e Bulaghi Proceedings.

Van Zeist, W. and Bottema, S. 1977. "Palynological investigations in western Iran", Palaeohistoria 19: 19-95.

- Smith, P.E.L., Palfenier-Wegter, R.M., Suwijn, M. and Casparie, W.A. 1984. "An archaeobotanical study of Ganj Dareh Tepe, Iran”, Palaeohistoria 26: 201-24.

Vanden Berghe, L. 1952. "Archaeologische Opzoekingen in de Marv Dasht Vlakte (Iran)", Jaarbericht Ex Orient Lux 12: 211-20. 
- 1954. "Archaeologische navorsingen in de omstreken van Persepolis", Jaarbericht Ex Orient Lux 13: $394-408$.

Vandiver, P. 1987. "Sequential slab construction; a conservative southwest Asiatic ceramic tradition, c. 7000-3000 B.C.", Paleorient 13.2: 9-35.

Voigt, M.M. 1983. Hajji Firuz Tepe, Iran: The Neolithic Settlement. Hasanlu Excavation Reports Volume 1, The University Museum, University of Pennsylvania, Philadelphia.

— and Dyson, R. H. 1992. "Chronology of Iran, c. 8000-2000 B.C.", in Ehrich, R.W. (ed.), Chronologies of Old World Archaeology, I \& II. Chicago University Press, Chicago: 122-78; 125-53.

Wasylikowa, K. 2005. "Palaeoecology of Lake Zeribar, Iran, in the Pleniglacial, Lateglacial and Holocene, reconstructed from plant macrofossils", Holocene 15: 720-35.

Weeks, L.R., Alizadeh, K., Niakan, L., Alamdari, K. (Trench A), Zeidi, M. and Khosrowzadeh, A. (Trench B). in press.
"Chapter 3. Excavations at Tol-e Nurabad", in Potts and Roustaei in press.

Wobst, M. 1974. "Boundary conditions for Paleolithic social systems: a simulation approach", American Antiquity 39: 147-78.

- 1977. "Stylistic variation and information exchange", in Cleland, C. (ed.), Papers for the Director: Research Essays in Honor of James B. Griffin. Ann Arbor: Museum of Anthropology, University of Michigan: 317-42.

Zagarell, A. 1982. The Prehistory of the Northeast Bahtiyari Mountains, Iran: The Rise of a Highland Way of Life. Beihefte zum Tübinger Atlas des Vorderen Orients, 42, Dr. Ludwig Reichert Verlag, Wiesbaden.

Zeder, M.A. and Hesse, B. 2000. "The initial domestication of goats (capra hircus) in the Zagros Mountains 10,000 years ago", Science 287: 2254-57.

Zeidi, M. McCall, B. and Khosrowzadeh, A. in press. "Survey of Dasht-e Rostam-e Yek and Dasht-e Rostam-e Do", in Potts and Roustaei in press. 